\title{
SCHOOL EFFECTS ON THE WELLBEING OF CHILDREN AND ADOLESCENTS
}

Francisco Juan García-Bacete ${ }^{1}$

Ghislaine Marande Perrin ${ }^{1}$

Barry H. Schneider ${ }^{2}$

Celine Blanchard ${ }^{2}$

${ }^{1}$ Universitat Jaume I. (Castellon, Spain)

${ }^{2}$ Ottawa University (Ontario K1N 6N, Canada)

\section{Acknowledgements}

The writing of this chapter was made possible partly thanks to research support grants awarded to the first author, from the Ministry of Education and Science (Project: Peer Rejection and Classroom Social Dynamics: A Multidisciplinary and Multi-methodological Approach; reference PSI2008-00541/PSIC) and from Bancaja Foundation / Universitat Jaume I (Project: Longitudinal Study of Peer Rejection in Interpersonal Context: an intervention program for 7-9 year-old children; reference P1-1B2009-33), and the granting of a 3 months stay at the Universitat Jaume I (from Abril1st. to June 30 ${ }^{\text {th }}, 2011$ ) to Ph.D. Barry H. Schneider from the Ministry of Science and Innovation within the National Program of Research Human Resources Mobility 2010, Subprogram Stays of experienced foreign teachers and researchers in Spanish centers (Reference SAB2010-0111)

\footnotetext{
Abstract

Well-being is a multidimensional construct, with psychological, physical and social components. As theoretical basis to help understand this concept and how it relates to school, we propose the Self-Determination Theory, which contends that self-determined motivation and personality integration, growth and well-being are dependent on a healthy balance of three innate psychological needs of autonomy, relatedness and competence. Thus, current indicators involve school effects on children's well-being, in many diverse modalities which have been explored.
} 
Some are described in this chapter, mainly: the importance of peer relationships; the benefits of friendship; the effects of schools in conjunction with some forms of family influence; the school climate in terms of safety and physical ecology; the relevance of the teacher input; the school goal structure and the implementation of cooperative learning. All these parameters have an influence in promoting optimal functioning among children and increasing their well-being by meeting the above mentioned needs. The empirical support for the importance of schools indicates significant small effects, which often translate into important real-life effects as it is admitted at present. The conclusion is that schools do make a difference in children's peer relationships and well-being.

\section{Structure of this chapter}

In this chapter, we describe the many ways in which schools can and do influence the well-being of their pupils.

The introduction addresses the main justifications for the interest in studying school effects on the development of children and adolescents, putting at issue whether schools are optimal contexts to promote their happiness and well-being.

In the second section, we begin with a consideration of the indicators of wellbeing that should be considered in weighing the effects of schools, thus clarifying what is meant by well-being accordingly to general and specific determinants. At this point we notice that, although schools are the context where the well-being of children and adolescents has been mostly studied, there is no consensus on the results, noting the absence of a theory or theories that would help understand the influence of schools on well-being and provide a framework for analysis and agenda. As a basis for that purpose we therefore propose the self-determination theory; we describe the theory and 
identify some specific indicators of well-being which have been highlighted by research based on this theory (intrapersonal, interpersonal and contextual factors). In accordance with the need for people to be/feel connected as it is proposed by the theory, the three subsections of this part show the importance of peer processes,- including friendships and peer preferences-, in school motivation and psychological well-being (peer relations as direct facilitators of well-being). Then we turn to the way in which school can help facilitate children's peer relations (direct way or social skills). The second section concludes focusing on the differential contributions of peers, family, school and family-school relationships to the child's well-being.

In the third section we continue enumerating the modalities by which schools exert their many and diverse influences. This part focuses on the various indirect ways in which schools contribute to positive social relationships between peers and their wellbeing. The section primarily deals with the climate and ecology of the school. We begin with a few lines about a necessary condition: schools must ensure the safety of children. Then the two largest subsections describe the contribution of physical ecology (arrangement of space, size of the school, pupil-teacher ratio, grades configurations) and of social ecology and culture (the teacher makes a difference, school climate and goal structure). The final two subsections examine two basic issues: one is more classical the initial differences between schools and how this can have an influence on the pupils' well-being-, and a more recent question, now arousing a great interest: the contribution of recreation time and extracurricular activities (informal ecology).

In the fourth section, we present a brief summary of the empirical evidence to date, together with a discussion of some methodological issues. This section includes 
results provided by research embedded into the school effects tradition, thereby indicating that there is still a rather incomplete connection between the two traditions, school effects and well-being indicators.

The essay concludes with some specific ideas for school-based intervention to promote the well-being of children and adolescents.

\section{Introduction}

The emerging clarity as to the basic nature of well-being has encompassed both subjective and objective indicators. Considering further the subjective perspective of the individual, Eminent Yale University political scientist Robert E. Lane (2000) points out that, despite the fact that, in the 50 years from 1950 to 2000, education and income have increased significantly in North America, ironically, subjective feelings of well-being have not increased at all. Unfortunately, it has been documented in a number of studies that life-satisfaction declines during the adolescent years (De Fraine et al. 2005; Currie et al. 2008; Huebner 2004). Perhaps this is partly due to dissatisfaction with schooling and with what goes on in schools. Indeed, many adolescents are bored much of the time at school (Larson 2000; Navarrate 1999). They often feel a profound sense of uncertainty about their future (Eccles et al. 2008). In most societies, it is understood that quality schooling constitutes an investment in the future of the society (Pianta 2006). In any case, it cannot be forgotten that children in developed countries spend great amount of time at school during stages of their development during which they are undergoing important physical, social and psychological change (Mortimer 2003; Roeser et al. 2009; Seilstrom and Brenberg 2006). Furthermore, it has been argued by many that one of the fundamental purposes of schools, though not by any means their sole purpose, is to promote 
children's long-term well-being (Garcia-Bacete 2009; Garcia-Bacete and Martinez-Gonzalez 2006).

Schools as important determinants of children's well-being

Before the 1970s, it was commonly believed that schools had no more than marginal effects on children's development and well-being (e.g., Rutter and Maughan 2002; Scheerens and Bosker 1997). Therefore, even though researchers often found it convenient to collect data in schools regarding children's and adolescents' well-being, little of this research took into account the many ways by which the school itself may influence the outcomes that are studied (Epstein and Karweit 1983). In sharp contrast, a few scholars assigned a primary role to the social skill of adjusting to the reality of the school situation and handling its interpersonal demands in an effective manner (Loranger 1984; Stephens 1976, 1981). However, starting in the 1970s, a number of somewhat serendipitous findings led to a greater appreciation of the fact that schools make a difference, in fact a substantial difference. For example, it was noticed in many longitudinal studies on children's well-being and adjustment that there were large differences among schools in their pupils' well-being that could not be explained by any variables other than those pertaining to the schools themselves (Rutter and Maughan 2002).

Another reason for greater interest in the effects of schools is better understanding of the implications of being literate for people's well-being. The Soviet psychologist Vygotsky (1978) emphasized the acquisition of literacy as the source of profound changes in the individual's thinking, and attributed considerable importance to the school as a venue for fostering development and well-being in general. Positive 
correlations between academic achievement, well-being and mental health attest to this (Gershoff and Aber 2006; Roeser et al. 1998b; Samdal et al. 1999).

In her persuasive treatise on happiness in education, Noddings (2003), an American philosopher and educationalist, begins with a reminder that Aristotle considered the pursuit of knowledge as happiness by itself. Plato believed that doing one's work well is a major source of happiness; achieving that is one of the aims of contemporary education. Noddings observes that personal individual happiness is not usually discussed as an aim of education although she believes it should be. She calls for more extensive reflection about what the purposes of education should be. Such reflection should hopefully lead to thinking about goals that go beyond the acquisition of basic academic content. According to her, schools should not only teach subject matter but also prepare students for what will make them happy as citizens with commitment to others, underprivileged people, homemakers, relationship partners, parents, and spiritual beings. Some may argue that these objectives are supposed to be those of families, as they once were. However, she insists that this is now the role of schools. An important part of the curriculum should be devoted to the nature of friendship, which might be taught through literature. Noddings argues that schools should provide a rich curriculum for every talent, pursuit of which will lead to happiness.

Are schools optimal contexts for healthy child development and well-being?

Educational theorists have referred to two distinct levels of school influence and socialization, the instrumental and the expressive (Bloom 1977; Isherwood and Ahola 1981). Isherwood and Ahola further subdivide the instrumental level into official instrumental and hidden instrumental features. Official instrumental aspects of school life have to do with the accomplishment of the school's official 
objectives such as the acquisition of academic skill and content. Hidden instrumental aspects pertain to efforts exerted to maintain the structure of the school system, such as reinforcement by teachers of conformity to the group structure and sanctions for the violations of school rules. In counterpoint to such formal, instrumental socialization are the experiences offered by means of interactions among pupils, sharing of perspectives and feelings. It is this expressive socialization that probably has more to do with pupil well-being although academic competence and learning to adapt to structured settings are adaptive as well. Ahola and Isherwood emphasize that teachers can structure their classroom environments so that instrumental and expressive socialization either compete or co-exist. If they compete, the classroom is likely to be one in which there is considerable tension.

An outstanding school could conceivably have much more of a protective influence than an ordinary one. There are many studies about the nature of schools that are particularly effective, including some research on the types of schools in socially disadvantaged neighborhoods where children learn well (Slavin 1998). However, most of that research has to do with academic achievement. Little is known about the schools that are effective in fostering children's well-being (Hedges et al.1994). However, there begins to be a growing interest in knowing whether schools have an effect on mental health and on social, behavioral, ethical and civic attitudes, as they have on students' academic results (Battistich et al.1999).

In fact, while it is surely a more frequent practice to apportion credit or blame for the way children turn out to their parents, it is by no means uncommon to attribute students' successes and failures at least partly to the effects of schools. Edmonds (1986) suggested that the school environment can be so potent in some extreme cases that it overrides virtually all other factors in determining at least how the child behaves at school, if not more generally. Edmonds' contention contrasts sharply with other viewpoints according to which the child's behavior at school passively mirrors the family environment and surrounding 
social conditions.

\section{General and School-Specific Indicators of Well-Being}

General indicators of well-being

The first hurdle in understanding how school effects are or can be related to children's well-being is to clarify what is meant by well-being. Many researchers and policy makers have approached their work on well-being in much the same way as famed trumpeter Louis Armstrong approaches his contributions to jazz music. When asked by a reporter to define jazz, Armstrong retorted that if you have to define it, you can never understand it. However, some reviewers of the burgeoning research literature on children's well-being have decried that state of confusion that has emerged from the lack of a clear definition of wellbeing common to researchers across the field. Several ideas repeatedly recur in the various distinctions that have been proposed (Casas 2010b). One is that well-being is a multidimensional construct, with psychological, physical and social components. Another is that well-being empowers the individual to participate actively and creatively in activities considered important in a person's culture. In turn, well-being is also the positive mental state that emerges from participation in these activities. Well-being is also understood in terms of the satisfaction of an individual's basic physical, psychological and social needs. Other notions of well-being focus on self-esteem, purpose in life and the person's general feelings about his or her life circumstances (Weisner 1998). In a review and critique of definitions of well-being, Pollard and Lee (2003) identified five distinct domains of well-being based on previous writings: physical, psychological, cognitive, social and economic. Researchers have included both positive and negative indicators of each of these domains. 
Looking historically at the attention that has been paid to the well-being of children, most attention seems to have been paid until recently to material indicators of the satisfaction of children's basic needs, starting with the most basic, survival but also including basic literacy. The adoption of the United Nations Convention on the Rights of the Child constituted an important turning point by providing a standard reference point for the study of child and adolescent wellbeing. In that document, children's rights were recognized as fundamental human rights. Children were thus considered worthy of actually having rights, which was not universally recognized at that time. Within the intellectual community, innovative theories about the course of child and adolescent developed surely helped inspire new perspectives on the nature of children's and adolescents' wellbeing. These theories included Erikson's $(1963,1968)$ theory of psychosocial development, Bronfenbrenner's (1979) ecological systems theory, and the stage-environment fit theory expounded by Eccles and Midgley (1989). Other contextual factors that spurred interest in children's wellbeing include the emergency of the sociology of childhood, social capital theory, new methodologies for studying childhood and emerging political forces in which the translation of political decisions into practical interventions have been emphasized.

Casas (2010b) notes that all these points focus on promoting positive life conditions and on microsocial indicators, in comparison to preventive approaches and macrosocial indicators, due to the cultural, spatial and temporal connotations of the indicators (White, 2008). As noted by Casas (2010a), although education is included in all the systems of well-being indicators that have been proposed, and that school is the setting where well-being in children and adolescents has been mostly studied (Huebner 2004), no general consensus has been reached so far. Nonetheless some of the general trends are: 1) there is a significant positive correlation between satisfaction at school and personal well-being (Huebner and Gilman 2006), and 2) satisfaction 
with school and learning decreases as age increases during the adolescence, more in boys than in girls (Eccles and Roeser 1999).

Similarly, despite a myriad of results, indicators and efforts to establish some system bringing order among them, there is still a lack of theories and models (Ochaita et al. 2010; Seilström and Bremberg 2006). Frones (2007) notes that the next crucial step for the field is to further elaborate theories and models. According to many, a developmental theory that posits the child's needs in relation to the school context should be constructed, explaining what the school context has to provide to meet these needs (Allardt 1989; Boyce et al. 1998; Eccles \& Midgley, 1989; Gambone et al. 2002; Ochaita et al. 2010; Pianta, 2006). School-specific indicators highlighted by self-determination theory

Self-determination theory (SDT) is a general theory of motivation that is useful in understanding emotion, cognition and behavior in all spheres of life. SDT advocates contend that self-determined motivation and personality integration, growth, and well-being are dependent on a healthy balance of three innate psychological needs (Deci and Ryan 2000; Ryan and Deci 2000). According to SDT, human beings must maintain a comfortable level of the three basic psychological needs of autonomy, relatedness, and competence in order to develop and function optimally. When these needs are sustained to a healthy psychological level, individuals are intrinsically motivated to engage in discovery activities. The need for autonomy refers to the experience of choice and volition, to feelings of agency or perception that one's actions are chosen and self-endorsed. It suggests that in order to be driving towards engaging in growth and learning activities one will need to feel that this is part of his choosing. It is important for individuals to feel that they are the sole initiators of their activities and that they are active agents in determining how their lives will unfold. For instance, students may report high levels of 
autonomy after having the opportunity to choose the topics for class presentations. Student may feel more engaged in doing homework if it was them who decided at what time of the day they feel they would be more productive. A student that feels that he can freely express his ideas and thoughts will report a high sense of autonomy. Allowing such flexibility will help sustain students' motivation by respecting their important need for voice and autonomy.

A second need put forward by SDT advocates is the need for relatedness. This refers to the feeling of being grounded in significant relationships, the feeling of connectedness, belongingness, and warmth with others. The unconditional feeling of being cared for and valued is essential for individuals to grow, to sustain integration and develop a strong sense of community belonging. For example, students are likely to feel a sense of relatedness if their teacher exhibits an empathetic attitude toward them or a concern for their well-being. A teacher or school principal who comments or shows genuine interest in a child's behaviors, family difficulties, taste for certain foods or clothes, is promoting a caring and secure environment, thus enhancing the feeling of being appreciated and of belonging. Parents who genuinely comfort their children, for example by taking a child in their arms, looking into the child's eyes, and providing them with security, promote children's motivation to grow and discover by fulfilling this need for relatedness and acceptance.

A third need which has been proposed as essential for growth and well-being is the need for competence. Competence refers to one's feelings of effectiveness and environmental mastery. For example, students would typically experience feelings of competence if they understood difficult material taught in class. Pupils will be more inclined to make decisions, to move toward growth activities if they feel they can succeed at them. On the other hand, sending a message doubting the child's competence may destroy the intrinsic motivation to grow and 
instead encourage the extrinsic motivation to prove one can do it. Although extrinsic motivation may be necessary and useful at times, intrinsic motivation is seen as optimal in SDT. Creating situations or finding solutions to help one achieve and discover the inner resources to achieve may prove to be more fruitful to sustain this important component. These three natural and basic ingredients work together to create growth, development and well-being (Weinstein and Ryan 2010). Need satisfaction is reflected by people's subjective experience of autonomy, competence, and relatedness. When studying need satisfaction using this framework, students' perceptions of need satisfaction are assessed (Grolnick et al. 1991; Guay et al. 2003; Guay and Vallerand 1997).

Empirical evidence supports the link between three needs and well-being in general (Weinstein and Ryan 2010) as well as in schools (Ryan and Deci 2009). More precisely, research in the educational setting has supported the assumption postulated by SDT that need satisfaction is associated with greater self-determined motivation and other positive educational outcomes. For example, perceived autonomy by students has been linked to students' self-report of task interest-enjoyment, and to observers' ratings of student task engagement and performance (Reeve and Jang, 2006). A study by Ryan and his colleagues (Ryan et al., 1994) showed that students who experience relatedness with teachers and parents internalize more forms of schoolrelated behavioral regulation (e.g., coping, positive affect, engagement, and capacity beliefs). Results of a study by Furrer and Skinner (2003) revealed an association between students' sense of relatedness to key figures and their emotional and behavioral engagement in school. A study by Veronneau and her colleagues (Veronneau et al. 2005) showed that all the three needs are related to well-being. Furthermore, the results revealed that competence emerged as a significant contributor to well-being among the sample of twelve-year old students. 
Other studies have demonstrated that self-determined motivation mediates the relationship between need satisfaction and educational outcomes. For instance, research has shown that perceived autonomy and competence is associated with students' academic selfdetermined motivation, and in turn, with better academic achievement (Fortier et al. 1995; Guay \& Vallerand 1997). Similarly, Ntoumanis (2005) found that perceived autonomy, competence, and relatedness in school physical education were associated with greater physical education self-determined motivation, and in turn, with greater behavioral engagement.

Self-determined motivation. A healthy balance of the three needs is the precursor of selfdetermined motivation. Self-determination theory distinguishes among different orientations towards behavior, focusing on the quality of motivation, which serves as a good predictor of selfregulation. Activities that are not inherently interesting can nevertheless be regulated autonomously if the individual endorses them or the value they represent. Deci and Ryan (2000) argue that external regulations are transformed into internal regulations through a process called internalization. Internalization is an important adaptive process that allows people to take in external goals and adopt them as their own. In doing so, individuals endorse the importance or value of many activities that may not in themselves be intrinsically motivating but that are necessary for the achievement of personal goals and well-being. To illustrate and organize the varying degrees of internalization, motivation is defined as a multidimensional construct. Each type of motivation corresponds to a different form of regulation that fits along a selfdetermination continuum. The different forms of regulation, in order from the lowest to the highest in terms of self-determination, are as follows: non-regulation, external regulation, introjected regulation, identified regulation, integrated regulation, and intrinsic regulation (Ryan and Deci, 2002). 
Non-regulation (i.e., amotivation) represents an absence of motivation and is reflected by a state of apathy, often brought on by an individual's perceived lack of contingency between his behavior and a desired outcome. External regulation represents the second lowest form of motivation. It typically occurs when an individual is motivated by external sources, either to obtain material or social rewards, or to avoid punishment. Often, in this situation, involvement in an activity, for reasons such as the outcome or the reward, will be short- lived, perhaps remaining just as long as the reward is available. Thus, creating a reading program where the focus is on a prize delivered after 10 books are read by pupils may overly emphasize this type of orientation. The pupils will focus their attention on the outcome and will most likely ignore the importance of enjoying their book.

Along the continuum, the first internally driven form of regulation is introjection. Despite its internalization, introjected regulation is still considered to be a relatively controlled form of regulation because it is characterized by self-pressures, such as avoiding feelings of guilt or pursuing feelings of pride. In this particular case, the energy stems from an internal pressure representative of behaviors instilled by one's environment and by significant others. In such cases, pupils engage in behaviors and activities because they feel they have to and because they want to avoid feeling guilty. Behaviors emerging from this kind of energy lead to negative affect and poor growth; thus, this form of motivation does not contribute to well-being.

Amotivation, external regulation and introjected regulation are further qualified as non self-determined motivation. Non self-determined types of motivation have been associated with negative emotions, cognitions and behaviors.

The next two forms of extrinsic regulation on the continuum are considered to be selfdetermined because they are more internalized and are experienced as more autonomous. With 
identified regulation, activities are perceived as valued and as chosen by the individual because engagement in these activities facilitates achievement of personally meaningful goals. An activity is fully endorsed by the self when it is in line with other goals and values within the individual. Identified regulation involves a conscious valuing of a behavioral goal or regulation, an acceptance of the behavior as personally important. However, SDT suggests that some identifications can be relatively compartmentalized o separated from one's other beliefs and values, in which case they may not reflect the person's overarching values in a given situation. Integrated regulation results when identifications have been evaluated and brought into congruence with personality endorsed values, goals, and needs that are already part of the self; nonetheless, although behaviors governed by integrated regulations are performed volitionally, they are still considered extrinsic because they are done to attain personally important outcomes rather than for their inherent interest and enjoyment.

The last form of regulation on the continuum is intrinsic regulation. This type of regulation is evidenced when people choose to engage in activities that provide them with feelings of great pleasure and satisfaction. No incentive is necessary to engage in the intrinsically motivated activity, as the activity provides enjoyment in and of itself.

In summary, the self-determination continuum, which differentiates among the six forms of self-regulation, represents the different reasons that motivate people to engage in various activities. While intrinsic regulation represents the hallmark of autonomous functioning, two forms of extrinsic regulation, namely identified and integrated, are also considered to be selfdetermined because they are internalized in the individual's sense of self and are perceived to be more autonomous (i.e., less controlling) than their less self-determined counterparts. 
Empirical validation of SDT. Past research has consistently demonstrated that compared to less self-determined motivation, self-determined motivation is associated with various positive consequences such as greater deep-level learning (Andriessen et al.2006; Simons et al. 2004), better performance (Simons et al., 2004), more interest/enjoyment (Black and Deci 2000 ; Simons et al., 2004), greater creativity (Amabile 1983), greater positive affect and effort in the classroom (Reeve et al. 2002; Vallerand 1997), less anxiety (Black and Deci 2000; Ryan and Connell 1989), and lower probability of dropping out of a class or school (Black and Deci 2000; Vallerand et al. 1997). Overall, findings show that academic self-determined motivation is associated with school engagement, as well as with favorable cognitive and affective learning experiences.

Over the years, research conducted on the dynamic function of the needs and on the consequences associated with each subtypes of regulation, has been and continues to be applied to diverse fields, including education. Precisely, past research and recent work grounded in selfdetermination are beneficial for the field of education. Additionally, theoretical concepts have developed and branched out to provide a more comprehensive view of intrapersonal, interpersonal and more general contextual factors influencing motivation and well-being in general and in school. In the next section, each of these will be introduced briefly.

Authenticity, mindfulness and intrinsic aspirations. Self-determination theory and extensions to it have salutary applications relevant to human development. These can be organized around the concepts of authenticity, mindfulness and intrinsic aspirations. Principles of authenticity have been explored extensively within self-determination (Kernis 2003; Kernis and Goldman 2006). Authenticity has been defined has 'the unobstructed operation of one's true core self in one's daily enterprise" (Kernis 2003, p.13). The concept is further decomposed into 
four components, namely, awareness, unbiased processing of information related to the self, behavior that is true to the self, and genuine relational orientation (see Kernis and Goldman 2006 for definition). It is suggested that striving for authenticity will favor internalization and integration of external factors. As well, authenticity is a precursor of mindfulness. It implies being highly aware of one's action and feelings without being ego-involved (Brown and Kasser 2004). It is the ability to attend to stimuli without embellishing them. The more one is focused on being connected to a true core self, the more he or she will develop the ability to attend to selfrelated stimuli and to process them truly. Furthermore, a mindful individual will be apt to chose and make decisions based on the needs and aspirations of a true self. Two types of aspirations have been proposed, notably, extrinsic and intrinsic aspirations (Kasser 2002). Extrinsic aspirations refer to strivings for fame and materialistic goods. Intrinsic aspirations refer to acceptance of the self, positive relationships with other, and a strong sense of connection with one's community. It has been shown that focusing on intrinsic aspirations is much more beneficial than aiming for extrinsic aspirations (see Kasser and Ryan 1993, 1996). Intrinsic aspirations are associated with psychological well-being while the opposite is true for extrinsic aspirations. These results have recently been supported in the education domain (Kasser and Ahuvia 2002; Henderson-King and Mitchell 2011). With regard to these intrapersonal concepts, more should be done to provide young people with the skills necessary to strive for more authenticity, for mindfulness and for intrinsic aspirations. Mentoring pupils and students is key to helping them develop such an orientation. Thus, the work emerging from self-determination theory is useful in better understanding how individuals can achieve greater grounding and become increasingly more responsible for their own development, growth, and well-being. Selfdetermination theory and cognitive evaluation theory have led to profitable research pertaining to 
how close others can impact the development of such an orientation. Several practical ways of achieving this are presented below.

Interpersonal style, teaching philosophy and their role in growth and well-being. A subtheory of self-determination theory, namely cognitive evaluation theory (CET), has promulgated research pinpointing interpersonal factors that may either undermine this naturally occurring phenomenon or to positively impact it. Ideally, parents and teachers should focus on sustaining self-determination and support internalization. CET suggests that some climates and some interpersonal styles and approaches sustain self-determination by respecting pupils' psychological needs. Other approaches, like a controlling one, will be detrimental. Indeed, a controlling interpersonal style will impoverish a subordinate's motivation (Blanchard et al. 2009; Roth et al., 2009; Reeve, 2009) In a similar way, a competitive climate in the classroom will lessen the feeling of competence (Reeve and Deci 1996), thus undermining motivation and wellbeing in the classroom. For this reason, many SDT advocates decry the negative impact of high school on motivation and on the development of the integrated self. Based on research revealing a decline in motivation when students enter high school, SDT advocates advise against large classes and multiple teachers for each class or pupil (Linnenbrink-Garcia and Fredricks 2008).

Parenting practices may also affect well-being of students and pupils by helping or hindering the satisfaction of the basic needs outlined above and by promoting or squelching intrinsic motivation. For example, a controlling parental style, through the use of discipline, reward systems and feedback, may have detrimental effect on the basic psychological needs (Farkas and Grolnick 2010; Grolnick and Pomerantz 2009 ). Research has repeatedly demonstrated that an autonomy-supportive approach and an environment providing structure will allow for growth, development and well-being (Deci and Ryan 2011). 
Reeves and others have delineated the core principles needed by schools to apply the self-determination principles (Reeve 2006, 2009; Reeve and Halusic 2009; Su and Reeve 2011). A healthy balance of all three needs will substantiate growth and well-being. Since individuals are naturally inclined to move towards growth (Knee and Uysal 2011), parents and teachers should be open-minded and aware of the existence of such needs in order to sustain selfdetermination and support internalization.

Self-determination theory in regard to school climate and the purposes of schools. In order for one to develop and experience well-being, pupils and students need to experience autonomy, relatedness and competence at a more general level. School culture and climate are key contributors to health and well-being in children (Linnenbrink-Garcia and Fredricks 2008; Reeve and Assor 2011). The school principal and the community in general have an important role to play in communicating school values, community values and societal values. It is important to develop and maintain a vision focusing on long-term development, instead of shortterm performance goals, and to then find the right tools to communicate such a vision. The sense of community that is developed reinforces the sense of belonging. Members of such communities, and especially pupil members, can then trust and aspire to become highly functional autonomous individuals. Within this context, autonomous individuals experience rich interpersonal relationships. In turn, they develop the ability to contribute and to give back to the community and society at large.

As it is at present, the school system seems to be supporting two different visions, one proclaiming good societal values and another focusing on academic achievement and performance. According to many critics, mass testing is overemphasized and creates a competitive and performance-oriented climate. This runs against the basic principles of self- 
determination theory. Therefore, SDT advocates are making it their responsibility to inform policy-makers of the detrimental impact of mass testing in the schools (Ryan and Brown 2005). Advocates believe that reflection on the needs and the development of the young members of society is necessary to better prepare them to take on societal responsibilities and make important life and societal decisions.

In summary, self-determination theory can be translated into practice by ensuring that everyday interactions are umbrella-led by a long-term approach to student and children development. Mainly focusing on achievements and performance will lead a student to perform but not necessarily to develop and fulfil all his/her potentials. Detecting and praising effort will do a world of good to develop initiative and a feeling of internal control. Using structure and an approach supportive of autonomy will surely contribute to the development of children and youth as they become members of psychologically healthy communities.

\section{Indicators based on school facilitation of rewarding interpersonal relationships}

As mentioned in the previous section, the needs for connectedness and participation in interpersonal relationships are considered as fundamental and universal in self-determination theory. There is growing evidence that peers processes are involved in the children's academic performance, their motivations and attitudes toward school, as well as in their self-perceptions and psychological well-being (Ryan 2000).This section provides an overview of the role of the school in fostering satisfying, positive relationships among its pupils.

In a cross-national study on the well-being of adolescents in the 27 countries that are members of the OCDE, Bradshaw and Richardson (2009) found that, cross-culturally perceptions of global well-being are highly correlated with satisfaction with relations with one's peers. In a 
recent study of Spanish schoolchildren between 7- and 16-year old, the participants mentioned that being with their friends was their favourite activity (Casas 2010b). Monjas, Sureda and GarcíaBacete (2008) found that 10 and 11 year-old Spanish students mentioned that the main reasons why they choose a peer as a friend are because he/she is friendly, kind, funny, both experience a mutual satisfaction, and relevant features of friendship are present in the relationship (trust, loyalty, support, help). Similarly, in a recent study of Finnish students at the end of their formal school experience, the participants were asked to identify the incidents during their entire school experiences that they considered crucial. The common theme among these incidents, whether they were salient because of the happy feelings they evoked or the hardship that ensued, was their interpersonal content (Pyhatlo et al. 2010). This will not surprise many keen observers of the school environment. At first glance, huge chunks of the school day appear to be devoted to academic lessons during which social interactions among the pupils are often not contemplated. This is far from true, even in secondary (high) schools. In their ethnographic exploration of two Canadian secondary schools, Isherwood and Ahola (1981) discovered almost constant communication among the pupils, including opportunities to form friendships and to determine and implement social acceptance and rejection. Thus, they seem to be manifesting the need for interpersonal relationships that is considered in SDT a fundamental human need.

The importance of such peer relationships for well-being in life has been explored, although much more research has been conducted with regard to obstacles to well-being than to peer relations as direct facilitators of well-being. By far, most of the attention in longitudinal studies of peer relations has been devoted to the long-term consequences of being disliked, aggressive, or withdrawn in large groups, such as classrooms or schools. However, it has been argued that this emphasis on rejection by the peer group as a whole 
obscures a potentially vital link between early peer relations and later adjustment that occurs because of the benefits of having even a single close friend (e.g. Furman and Robbins 1985). Nowhere are the advantages of friendship assigned as much weight as in the influential theories of the American psychiatrist Harry Stack Sullivan (1953). Sullivan was born in the small agricultural town of Norwich, New York in 1892. Appalled by the 'waste of human abilities' (Perry 1982, p. 5) that he observed in his work as a psychiatrist, a researcher and a consultant for Selective (conscription) Service during World War II, Sullivan became determined to increase the available base of knowledge about raising children. He developed an interpersonal theory of development in which friendships play a key role. Sullivan posited that friendships are necessary because they satisfy the human need for interpersonal intimacy and they help develop vital social skills and competencies (Newcomb and Bagwell 1996). More specifically, Sullivan proposed that the formation of close, one-on-one relationships during pre-adolescence is crucial to the acquisition of these social competencies (Kerns 1996). These relationships, called chumships, prevent loneliness and enhance children's sense of self-worth. Their relationships to their chums provide children with a means to develop sensitivity to others' problems and perspectives of mutuality in their interpersonal relations. This relational base is reflected in intimate heterosexual relationships later on.

Popularity and friendship may contribute in different ways to children's wellbeing, although children who are generally popular with peers also have a greater likelihood than others of cultivating close friendships. There are convincing reasons why close friendships might have particular implications for coping with life's challenges. A relationship with a close friend is characterized by intimacy, unlike children's more 
superficial relations with the classmates who might regard one as popular. Learning how to form and manage close, intimate relationships may lead to having a close friend to serve as confidant during moments of stress and to having someone who would provide considerable time and practical help when needed the most. Participation in a close friendship is also thought to foster flexible thinking in many ways; flexible thinking is known to relate to successful coping with stress (Cantor and Harlow 1994). One of the modes of flexible thinking that is associated with adaptation in the face of adversity is the ability to understand how other people think about things and appreciate that they may have views about a specific situation that are quite different from one's own (see Selman et al. 1997, for a detailed exposition of how this might occur). It has been emphasized that friends not only gain more knowledge about interpersonal relationships from their friendships than from their contacts with acquaintances, but that one gains in friendship qualitatively different knowledge about relationships, knowledge and skills that are particular to close, supportive bonds (Barr 1997). In contrast, having no friends at school leads to disengagement and alienation, which may in turn precipitate school dropout (Kagan 1990).

Despite the widespread interest in Sullivan's theory, there is much less longitudinal research documenting the long-term implications of friendship during the childhood years specifically than there is with regard to acceptance or rejection by peers in large groups; this limited literature is summarized by Bagwell and Schmidt (2011), by Hartup and Stevens (1997) and by Berndt (1999). Indeed, Sullivan emphasized 'chumship' at the very beginning of adolescence; perhaps for that reason, more longitudinal research documenting the benefits of friendship has followed individuals 
from adolescence into early adulthood. Most of the longitudinal studies conducted with children involve follow-ups for relatively short periods of time, typically less than two years. The range of outcome measures of adjustment is also limited, with more data available about the implications of friendship for adjustment to school than with regard to any other aspect of well-being.

Nevertheless, it is important to note that, in the few specific studies that have been conducted on the issue, friendship is strongly correlated with happiness among children and adolescents. This has been found especially in studies conducted in the U.K. by researchers inspired by Michael Argyle's theories about human adolescence (Argyle 1987; Cheng and Furnham 2002). Interestingly, it has been found that the children of parents who themselves have wide networks of friends are happier than other children. Among the many possible ways that might account for this is the possibility that the parents model for their children the abilities needed to make and keep friends (Homel et al. 1987).

It is sometimes thought that the support of friends is inconsequential in cultures characterized by strong family bonds and a collectivistic value orientation. However, indications of this have been found in only a minority of published studies. For example, in their comparisons of the friendships of children and youth in the U.S. and Indonesia, French, Pidada and Victor (2005) found that the typical friendships of the Indonesian participants were not as intimate or close as those of the U.S. Sample (French et al. 2005). However, most studies of friendship in collectivistic societies indicate the opposite, including studies of children and youth in Japan (Dekovic et al. 2002; Schneider et al. 2011) and Cuba (Schneider et al. 2011). Schneider, Lee and Alvarez-Valdivia (2011) 
observed that in highly collectivistic societies, close friends may have a specific role in promoting well-being. Friends may provide relief from the intense pressures to confirm and, in both Japan and Cuba, the pressures to succeed at school. Thus, the rich family life of many collectivistic, family-oriented societies may not compete at all with the richness of interactions with friends; in fact, learning how to relate harmoniously with family members may prepare the child for the challenges of initiating and maintaining close friendship.

Several excellent studies have been conducted to gauge the importance of friendship in the transition to a new school, either at the beginning of primary school at age 5 or 6 years (e.g. Ladd et al. 1996), or between primary and middle school, at about age 12 years (e.g. Berndt and Keefe 1995). In general, the supportiveness or closeness of friends seems to facilitate successful adaptation to the new school, whereas 'head counts' of the number of friends one has, regardless of how close they are as friends or how positive they are as models of behavior, seem to be unrelated to adjustment. Schneider, Tomada, Normand, Tonci and de Domini (2008) found that social support from close friends was an important predictor of successful transition to middle school in Italy, where there is a very drastic transition from highly child-centered elementary school to a very traditional middle-school curriculum focused primarily on the mastery of academic subjects. In a Canadian study conducted with participants about the same age, Oberle, Schonert-Reichl and Zumbo (2011) also found that positive peer relationships were correlated significantly with life satisfaction.

As it has been described by Gifford-Smith and Brownell (2003), peer relationships are influenced by the values and discipline policies of schools, the 
emphasis on promoting positive social relationships and preventing bullying both inside and outside the classroom, and the teachers' ability and knowledge about how to promote a proper adjustment between peers. On the other hand, what happens in the school and in the classrooms is affected by current and past peer relationships. For instance, the number and type of peer groups in a high school may affect the nature of the curriculum actually taught, the discipline policy and the school climate (Gambone et al. 2002). Negotiations among adolescents about their membership of a clique and conflicts among members are a major source of school discipline referrals and the principal target of the bullying prevention strategies and classroom/class management. Peers are the most powerful influence on daily behaviors in the school, time spent on homework and sense of fun in school (Steinberg and Brown 1989).

Peers influence each other and, thus, may inculcate positive or negative values about schools and schooling or may cross-fertilize alienation from the educational enterprise. Academically successful students and students who hold high expectations for themselves tend to affiliate with peers who are highly motivated academically, value good grades and are similarly involved in academics (Berndt and Keefe 1995; Kiuru et al. 2007; Ryan 2001). Adolescents with high achieving friends show improvement in their own academic achievement over time and increased involvement in school (e.g., Wentzel et al. 2004). In addition, friends' academic competence and support have been shown to be associated with students' own academic competence (Bissell-Harvan and Loken 2009). On the other hand, it is very possible for conflicts among peers to become manifest in disciplinary encounters at school (Steinberg and Brown 1989).

One of the major functions of friends and other peers is the provision of social 
support. According to a meta-analysis by Chu, Saucier and Hafner (2010), which encompassed 247 original studies, social support among children and adolescents is correlated significantly with their well-being. This may occur because social support promotes positive self-esteem, which in turn leads to perceptions of well-being. Social support by peers and involvement in close friendship may indirectly promote well-being by mitigating the negative effects of impediments to well-being. The protective effects of friendship against bullying have been the most widely studied. Having a good friend at school directly reduces the likelihood of being bullied. This may occur because the potential bully refrains from attacking peers who may subsequently be protected by their friends (Hodges et al.1999). Furthermore, even if having a friend does not totally eliminate the risk of being bullied, the support of friends and others may reduce the psychological consequences of being bullied. For example, in a large-scale $(n=4331)$ study of life satisfaction among primary and middle-school pupils, Flaspohler and his colleagues (2009) found that being bullied constituted, not surprisingly, a major impediment to life satisfaction. However, their mediational analysis revealed that, among students who were bullied, those who experienced positive support from peers and teachers were more satisfied with life.

In a creative and informative case study of 11 Australian schools noted for low incidences of bullying, McGrath and Noble (2010) found that one of the distinguishing features of those schools was a "relationship culture" in which the development of positive peer relationships was emphasized. Other features were a high priority placed on pupil well-being, effective leadership by the school administration and effective management of pupil behavior. 


\section{Direct Facilitation of Interpersonal Relationships at School}

Given the importance of positive peer relationships and the undeniable fact that such relationships are, to a considerable degree, nurtured at school, we now turn to the ways in which schools can help facilitate children's peer relations. We begin with direct instruction or social skills training. However, it is important not to overlook the many indirect ways in which schools can help or hinder the relationships of their pupils; these pathways are considered in the next section.

E. Lakin Phillips (1978) articulated perhaps the most eloquent theory-grounded proposal for a social competence curriculum. He called on schools to help children build some degree of tolerance for adverseness and annoyances, but also learn to solve the interpersonal differences which will inevitably arise. Such a curriculum should feature a realistic sequence of clearly-stated goals with the development of competence in the long term, not just the resolution of immediate classroom issues. According to Phillips, the curriculum should strive to reduce hostility toward others and impulsive reacting. It should emphasize ethical obligations towards other people. Phillips insisted that in a situation of person-environment conflict, it is easier to change the individual than to change the environment. It is important to note that many critics would disagree with that contention.

A variety of methods are used to facilitate peer relationships in schools. In a one-on-one coaching procedure, the "coach" provides ideas or concepts about social interaction, asks the child to generate specific behavioral examples of each, and encourages the child to use the concepts and monitor his/her own behavior (Asher 1985). Modelling approaches feature either filmed (Schneider and Byrne 1987) or role-play (Goldstein and Glick 1987) models of skillful behaviors. Systematic training in solving social problems is often found more suitable for whole-class instruction on a preventive basis. In a typical problem-solving intervention, children learn to identify the problem they are facing, consider different ways that they could respond to it and decide which of the ways is likely 
to lead to the best outcome. They may also plan how to implement the solution, practicing it via roleplay with feedback from the teacher or group leader. Recent innovations include the delivery of social skills training of several types by computer (Bosworth et al. 1998). Panacea this is not: getting the children to properly attend to the skills taught on line and actually use them off line is a formidable obstacle (Doo 2006).

Adalbjarnardottir (1991) conducted a particularly interesting intervention designed to enhance children's ability to negotiate with classmates and teachers. Eight Icelandic primary school classes were randomly assigned to either treatment or control conditions. The intervention consisted of focused training in solving interpersonal conflicts, and was administered to four classes as a whole. A semistructured interview was conducted at the beginning of the school year and repeated at the end. The children's interpersonal negotiation style was also observed directly in the classroom. Their interactions were rated, first of all, as either submissive or assertive. They were also coded according to the degree to which the actions reflected a sophisticated understanding of other persons' perspectives regarding the situation observed. Subjects who had received the intervention developed more mature negotiation strategies over the school year according to both the interviews and observations. It is interesting to note that the observational data indicate improvement for situations involving classmates but not teachers, suggesting that youngsters may have more difficulty understanding the perspectives and needs of adults even after intervention. Abalbjarndottir's study is of particular value because its outcome measures, which included both an interview and direct observations, were devised to assess very directly the specific outcome targeted by the intervention.

How effective is this direct approach to facilitation of peer relations among schoolchildren? Three meta-analyses indicate some degree of success, meaning that social-skills training is worth doing even if its effectiveness is not without limits. The major problem is achieving generalization and 
maintenance - getting the children to use the skills they have learned (as they usually do) in situations other than the one in which the instruction occurred (Erwin 1994; Beelman et al. 1994; Schneider 1992). Importantly, these meta-analyses focused on the effects of social skills training on different forms of maladjustment, such as aggression and social withdrawal or shyness. Little research attention has been paid to the possible benefits of social skills training for the well-being of children and adolescents who display no marked signs of maladjustment. In an interesting recent innovation, Ruini and her Italian colleagues (Ruini et al. 2009) introduced a more positively-valenced classroom-wide intervention focusing on the expression of emotion and on positive, friendly peer interactions. Their preliminary intervention was found to be effective in increasing pupils' scores on self-report questionnaires of well-being.

Unfortunately, though, few interventions have been planned to take into account the interaction of the intervention content with the classroom or school ecology. Should we expect a lesson on cooperation to have any substantial bearing on behavior in a classroom with a highly competitive goal structure? If effective problem-solving is taught as an isolated instructional unit, but infractions are handled in an impulsive, angry fashion, is there any benefit derived from the abstract tutelage on how to deal with irritants? The following sections suggest aspects of the whole-school environment that can affect peer relationships and pupil well-being.

\section{School and Family Influences, in Concert or in Opposition}

Researchers have invested heavily in comparing the value of social support from parents and from peers, although as it will be discussed shortly, having supportive parents does not usually mean having unsupportive peers and vice versa. Indeed, deSanctis King and colleagues (2006), in a study conducted with American pupils 11-19 years old, found that school satisfaction correlated positively with support received from the family. In any 
case, support from peers and parents may have different functions. Children and, especially, adolescents, may be more comfortable discussing with peers than with parents any problems that arise in their interactions with peers. They may also be happier with the responses given by their peers (e.g., Hoffman et al. 1988).

Epstein (1983) contended that until the early nineteenth century, the goals and practices of families usually matched the goals and practices of schools, with clergy often delivering prescriptions for both. However, mismatch between home and school environments is much more possible nowadays. The transition from home to school (or preschool) environments often brings children from family settings which vary considerably to educational settings that tend to be much more uniform. While parents may cultivate, or at least tolerate, a wide range of social behavior in children, formal education traditionally requires far more circumscribed patterns of social interaction. Where the social norms of the school differ markedly from those of the home, children are thought to have particular difficulty becoming competent at social interaction in the classroom (Flourio-Ruane 1989; Hansen 1986; Weinstein 1991). Nevertheless, the consequences of this mismatch in interaction rules seem more serious in classrooms where there is less flexibility in permissible behavior and where behavioral rules are more strictly enforced (Hansen 1986).

In most cases, children's behavior at school is probably quite similar to their behavior at home. This was confirmed, for example, by Hinde, Stevenson-Hinde and Tamplin (1985) who compared observations of children's behavior at preschool with parents' reports of behavior at home. Despite their findings, it should not be inferred conclusively that schools and families influence exactly the same aspects of well-being and personal/social competence. There has been some suggestion that schools may influence more extensively the practical 
aspects of getting along with others whereas families may influence children's values

(Klindova, 1985). Siblings may emerge as important socializing agents whose influences may reinforce, complement or contradict those of parents (Berndt and Bulleit 1985).

In most studies that have explored both school and family influences, family variables tend to explain statistically a greater portion of the variance than school variables (Good and Brophy 1986). Good and Brophy pointed out that this may be because of restricted range. In most Western countries, there are undeniable differences among schools but there is also a high degree of similarity among them in terms of general organization and the content of instruction. This may not necessarily be true in all societies. Heyneman and Loxley's (1983) review indicates that school and teacher characteristics play a far greater role in developing societies. It is also possible that some types of support from teachers may be particularly important to immigrant children and youth in multicultural schools in Western countries. This may be because the parents of immigrant children may not have sufficient familiarity with the host culture to help the immigrant children in their navigation of the countries to which they have immigrated (Vedder et al. 2005).

A positive school environment may serve as a buffer for a child undergoing family stress but it would be highly naïve to expect good schools to cancel out the effects of negative homes (see Eccles et al. 2008). Peres and Pasternak (1991) studied the adjustment of 314 Israeli primary school children whose parents were divorced. In the six schools studied that were conventional in terms of their organization, climates and routines, the children from divorced families displayed problems in relating to their peers. This effect was totally absent in an experimental school where children participated more extensively in decisions about what they would do at school and stayed at school for a much longer school day. Of course, 
Peres and Pasternak's findings are only suggestive and cannot be interpreted as indicating causation.

The family-school relationships are a relevant indicator of children's academic success and their general well-being, as well as an important factor in the protection of children and the prevention of child maltreatment (Melton et al. 2000), especially for children at risk (Christenson and Sheridan 2001). Having a strong connection between families and schools would directly increase children's benefits and create stronger communities, resulting in a significant rise in children's well-being (Ben-Arieh et al. 2009; Henderson and Mapp 2002) .

Concrete steps can be taken to improve the coordination of positive home and school influences (Forest and García-Bacete 2006; García-Bacete and Traver 2010; Hoover-Dempsey et al.2005). Many theorists emphasize the role of family involvement in the school (Bronfenbrenner 1979; Christenson 2004; Clarke et al. 2010; Epstein, 1997; García-Bacete, 1998; Marjoribanks 2004), although research evidence of this remains sparse (AlvarezValdivia et al., in press; Booth and Dunn 1996; Jowett et al.1999; Rutter and Maughan 2002) and furthermore perceptions of parents, teachers and students differ from each other (Ben-Arieh et al. 2009; García-Bacete 2003, 2006).

\section{Modalities of School Influence}

Schools are multilayered, multidimensional and dynamic entities (Boyce et al. 1998; Pianta 2006; Roeser 1998). Therefore, their potential influences occur at many different levels.

School Climate: what kind of beast?

Anderson (1982) clarified the concept of school climate by recalling Halpin and Croft's analogy that "climate" is to an organization what "personality" is to an individual, as well as Nwankwo's 
definition of school climate as the general "we-feeling" or group sub-culture of the school. Anderson evoked the metaphors of several types of beast in portraying the variations in attitude towards the concept of school climate. The albatross regards school climate as something which can be defined and which has an impact on children, but does not consider school climate a worthwhile focus of enquiry because it is not amenable to manipulation. Another group of critics takes on many characteristics of the unicorn - the study of school climate is seen as desirable in theory, but not likely to be successful, like a beautiful beast which can never be found. Such pessimism about being able to measure and study school climate is partly based on the observation that the climate of each classroom within a school may be very different, precluding any meaningful generalization about the overall "we-feeling" of the organization. Making matters worse, any measurement of school characteristics will be hopelessly confounded by individual student characteristics.

As researchers overcome the shortcomings of earlier efforts, the image of a phoenix has become more prevalent. Earlier studies often used measures that were convenient but grossly inadequate, and looked at a few isolated aspects of school functioning, leading to few findings of significance (Brookover et al. 1979). Their contemporary counterparts have adopted more comprehensive depictions of the workings of schools, yielding more encouraging indicators that schools do indeed make a difference.

Conceptual models developed by Tagiuri (1968) and Moos (1979) have been influential in developing a vocabulary for describing school climate. There are several salient dimensions useful in delineating the climate or atmosphere of a school or organization. The first dimension is the physical ecology of the school, its building, furniture, maintenance, lighting, equipment, utilization of space, etc. The social system or social structure refers to the implicit or explicit patterns or rules of social interaction in the school. The term school culture is used in this literature to refer to the beliefs or values 
of the individuals involved. In all major studies, these variables are studied in light of intake or milieu variables, i.e. the socioeconomic and educational background of the pupils and staff. Theoretical models differ as to whether these variables operate in a simple additive fashion or whether they interact to influence the outcomes of schooling. Anderson (1982) also described a useful mediated model. The first is a direct input-output pathway: intake or background characteristics have major and direct impact on the dependent variable. In the two other pathways of influence, these background variables affect the social structure and culture of a school, which in turn affect the student outcome.

\section{School climate and safety}

One important aspect of school climate is the real and perceived safety of the school. Gershoff and Aber (2006) found that $6 \%$ of students reported having sometimes or always fears about their safety at school. School violence is associated with anxiety, depression, general trauma, violent behavior, fear, avoidance and school dropout (Addington et al. 2002). Students who reported that their school was dangerous had a lower sense of school efficacy (Bowen et al.1998). Being worried about the own safety may affect the disposition, availability and motivation in learning (Eccles and Roeser 2009).

Proponents of whole-school anti-bullying approaches often focus on the school's disciplinary standards. However, it has been found that many aspects of school climate, including positive pupilteacher relations, are linked with safety, danger, and rates of bullying (Gregory et al. 2010; Richard et al., in press). Eccles and Roeser (2009) found that most of the acts of violence took place in what they called " undefined public spaces", non-instructional spaces in which students move before and after school and between classes (parking, hall, restrooms, playing field, cafeteria , ...). Bullying, an obvious threat to well-being, is known to occur when there are spaces in the school that are little or not at all supervised by adults (Astor, 1998) . 


\section{Physical Ecology of the School}

Arrangement of space. Psychologists have long been aware that the physical arrangement of a school or workplace influences the nature and extent of the social interaction that occurs within (Getzels, 1975; Lewin et al. 1939; Moreno, 1953). Kurt Lewin (Lewin et al.1939) conducted a series of "group climate" studies, in which physical ecology was an important element. He introduced the metaphor of a "circular classroom" — as opposed to the traditional "square" or rectangular arrangement of pupils in rows--as a way of encouraging everyone to face each other and interact more cooperatively. Lewin's theories of context were quite complex (Lewin, 1954), emphasizing the interaction of an individual's personal characteristics, personal characteristics of peers and characteristics of the physical setting. More recently, Charlebois et al. (1992) studied the seating arrangements of Montreal primary-school classrooms over a 3-year period. They found that boys identified as socially at-risk were almost always seated either at the very front or very rear of the classroom. When the same subjects were located in classrooms 2 years later, a striking $84 \%$ were assigned seats in the same zones. Unfortunately, a high proportion of teacher attention and feedback was directed at the middle rows. This study illustrates the importance of considering the interaction of physical ecology and subject characteristics.

Prohansky (1974) noted that if, as part of the socialization process, the child internalizes representations of significant others, of the roles he must play in groups and of unique interpersonal experiences he/she has encountered, there must also be some internalization of the places which help define socialization behaviors. Interactions with the physical setting in which satisfactions and frustrations occur and in which feelings of competence or incompetence are nurtured must be salient features of the individual's experience of important life events. Prohansky argued that if individuals express their identities in the ways they structure, decorate and maintain important physical settings, the 
converse must he true: the contexts which have helped define an individual's development must be expressed in the structure of that person's identity.

Lewin's context theory, mentioned above, emphasized the effects of the arrangement of the learning setting as well as the interaction between the arrangement of space and individual characteristics. Optimal organization of physical space has received considerable attention, culminating in a debate between open and close-space classrooms. In contrast, there has been relatively little systematic study of the interface of space arrangements context and individual differences among pupils (Bronfenbrenner and Crouter 1983; Legendre 1989). The technique of behavioral mapping (Ittelson et al. 1970) has greatly facilitated the study of links between arrangement of space and social interaction among its occupants. Berg, Segers and Cillessen (2011) conducted in 27 fifth- and sixth grade classrooms an experimental manipulation to determine the effect of distance between classmates on peer affiliations and classroom climate. In the experimental condition, children who did not like each other were placed closer together for several weeks in order to promote more positive peer relations. The decrease in distance led to higher likeability ratings for children who were perceived most negatively at the beginning of the school year. In addition, a reduction in peer-reported victimization and social withdrawal nominations was found. The results suggest that the classroom seating arrangement can be used as a tool to improve liking among peers and reduce peer-reported problem behaviors in the classroom, thus increasing children's well-being.

In some countries, schools in disadvantaged neighborhoods may have relatively bare, poorly equipped outdoor playgrounds. Parents and teachers may hope that the provision of play structures and gymnastic equipment will help correct problematic social interactions in these schools. However, this is not supported by the limited data available (Johnson 1935; Weinstein and Pinciotti 1988).

Play and classroom settings may be divided into separate compartments or feature no visual 
boundaries. Manetti and Campart $(1987,1989)$ conducted an experimental study of the use of space during indoor play by preschoolers in a disadvantaged area of central Genoa. The furniture was rearranged in order to physically divide the classroom into four sectors; storage shelves were used as dividers. This division resulted in a dramatic increase in social interaction. This may be because of the greater provision for privacy or because the monolithic and relatively barren open space was converted into more useable play areas.

Pellegrini and Perlmutter (1989) conducted a multidimensional observational study in order to determine whether certain types of play occur more frequently in certain areas of the preschool classroom. In general. the type of play props provided influenced the social level of play. The presence of both adults and peers also affected play patterns. Droege and Howes (1991) conducted an observational study with California preschoolers to determine whether social pretend play occurs in certain areas of the daycare center. Droege and Howes suggested that planners of daycare environments provide for children's apparent needs for a physical setting in which this type of play seems likely to occur.

Other data strongly suggest that young children's use of space depends heavily on certain individual child characteristics, including social competence, as well as the simultaneous use of space by the teacher or caregiver (Legendre 1989). Legendre (1987) found that in preschools where there were many visual boundaries, children generally spent more time in close proximity to adults. Children who were socially competent exhibited greater security in venturing more frequently to areas separated by visual boundaries from the adult caregiver. Nevertheless, there was relatively little dyadic interactive play in parts of the room without visual contact with the caregiver. Presumably, the absence of visual obstacles would permit children to play in all areas without sacrificing proximity to the adult caregiver (see Neill, 1982). Thus, there are inconsistencies between these results and those of Manetti and 
Campart, discussed above, which will hopefully be resolved as more studies appear.

Most primary schools have by now rejected the "open-space" architecture which was advocated energetically in the 1970s as a vehicle for enhancing interpersonal interaction within schools. In retrospect, it may have been naive to expect that simply removing walls and rearranging furniture would bring about fundamental change in the activities which take place within the school (Giaconia and Hedges 1982). Fortunately, the co-operative learning movement has featured rearrangement of space and furniture as an adjunct to the redirectional of the goal structure of the school's programme of academic instruction, not as an isolated intervention.

In summary, research documenting the effects of the classroom setting on children's social interaction has not only shown that the physical ecology of the classroom can have an important impact, but has begun to consider the interaction between the physical and human ecology.

Size of the school. Early research on school climate (McDill and Rigsby 1973: Weber 1971) explored the link between the size of schools and the academic achievement of pupils and their general satisfaction with schooling. These studies yielded largely non-significant findings, and have been criticized for their simplistic methodology and failure to look at the human ecology of the school together with the physical ecology. Similarly, Rutter and his colleagues (1979), studying the school climates of ten inner-city London secondary schools, found that the size of the school had little to do with the pupils' attention, achievement, attendance or with the delinquency rate of pupils. Thus, school size has, on the whole, been dismissed as a productive variable in school climate research.

The specific instance of school size in relation to children's social competence may warrant an exception. LaFreniere and Sroufe (1985) compared the social competence (as measured by sociometrics and direct observation of classroom behavior) of forty 4- and 5-year-olds in two preschool classrooms. One of the classrooms enrolled fifteen children, the other twenty-four. This study is 
particularly interesting because it explored the fifteen effects of class size in conjunction with the children's attachment history. In the larger class particularly, children with histories of anxious attachment with their mothers were more likely to be "swept away in the contagion of activity and judged to be out of control" (p. 66). Thus, LaFreniere and Sroufe's study, among others, illustrates the importance of considering individual child differences in assessing the impact of the school's physical ecology.

Coleman (1961) observed that in larger schools a student's sociometric status may tend to "blur". Pupils do not end up in coherent status groups, with the popular ones at the top and the rejected pupils at the bottom of the hierarchy. Instead, the social hierarchy of the school is less well-defined, and it is more likely that larger numbers of social subgroups will form, each of whom will have its own leaders and rejects. Thus, there will be less consensus with regard to who is most and least liked, and it is more likely that a given youngster will be well-liked in one particular social sub-group, which is defined by specific interests (athletic, artistic, social ), though not well-liked in another, dissimilar subgroup. Caulfield (1980) interviewed a number of children whose social adjustment had improved over several years. The youngsters whose sociometric status had improved were asked to speculate about the reasons. They very often cited a move to a larger school.

Grabe (1981) noted that in smaller schools there tends to be greater participation in extracurricular athletic, social and artistic activities. Therefore, there is greater identification with the school and its social group, at least for those who participate. However, as such extracurricular activities dominate the atmosphere of a small school, there is also a heightened sense of alienation and rejection among those who do not identify with the somewhat uniform general atmosphere of the small school. Similar findings were obtained in the classic study by Barker and Gump (1964), and in recent studies (Hawkins et al., 2008), and result in greater bonds between student and school, 
motivation for learning, achievement and engagement. However, as pointed out by Coleman (1961), the impact of school on one's peer relations may depend on the size of the community. In a smaller community, all potential friends are likely to attend the same school; presumably, in a smaller community, the consequences of being rejected by a particular social group are also greater because there are not many other social groups available.

The widespread concern in many countries about violence in inner-city schools might suggest that larger, urban schools are characterized by higher levels of aggression. However, Olweus's pioneering studies of bully-victim problems in Sweden, Norway and Finland suggest otherwise. Data are available from over 700 schools, ranging from tiny, rural schools (the smallest of which enrolled forty-three students) to large urban schools. There is no indication at all of any relation between school size (or class size) and the frequency of bullying (Olweus 1991).

As children progress in their studies, they are transferred to large, less personal schools in most countries. This transition to a larger school has often negative consequences, including disruptions of friendship networks, lower participation in school activities and more aggressive behavior (Hawkins and Berndt 1985; Lipsitz 1984).

Pupil-teacher ratio. Because of the implications for public policy and public finance, few dimensions of the school experience have been studied as extensively as class size. A complete review of this literature is beyond the scope of this essay. The consensus is that, within the range of class size that is typical of most school systems, i.e., 25 to 30 pupils, class size makes little tangible difference (Bennett 1998; Goldstein et al. 2000). However, very small classes, with, for example 8-15 pupils per teacher, may be beneficial to pupils with particular learning or emotional problems (Finn et al. 2001; Goldstein et al. 2000). Importantly, though, any benefits from reduced class size may only emerge if the teacher takes advantage of the opportunity to provide more individual attention to the pupils (Pianta 
2006; Rutter and Maughan 2002).

Grades configurations. Another contextual feature is the grades configuration. Eccles, Lord and Migdley (1991) found that adolescents who attended K-8 schools outperformed those who attended 6-7-8 grades in a middle or junior high school. It should be clarified that $74 \%$ of the K8 schools were Catholic and moreover they had fewer students than public middle and junior high school. Leithwood and Jantzi (2009), after reviewing studies on the school size and the grades configuration, stated that the most effective K-8 schools were those with 500-300 students or less, while the ideal K $9-12$ schools were those attending between 600 and1000 students. However, as noted by Wyse, Keesler and Schneider (2008), the impact of the school size on achievement depends on the quality of education: if the school focuses primarily on the social climate and spends a limited focus on the academic pressure, students feel at ease in this school, but their academic achievement is not higher than the one of students attending larger schools. Social and Cultural Ecology of the School

The social and cultural ecology of the school includes five major components: the teachers, the diverse elements of social climate (behavioral, supportive, moral), the goal structure, the recreation time and extracurricular activities, and the student body Does the teacher make a difference? The teacher's role is key in his/her classroom. Teachers contribute to well-being in at least four differential aspects : as a source of social support, in their feedback to pupils, showing optimism and confidence, and depending on their leadership style and organization of the classroom.

Teacher as a source of social support. Pupils often report that their teachers are important sources of social support. In fact, in the meta-analysis of 247 studies by Chu, Saucier and Hafner (2010), teacher support emerged as a stronger correlate of well-being than family or friend support 
(although these sources of support were still significant correlates). Teacher support is often of particular importance to children and adolescents who bring personal problems with them to school (Gambone et al. 2002). Teacher support may take many forms, ranging from tangible assistance with academics and monitoring of progress to manifestation of respect for the pupil as an individual (Burchinal et al. 2008; Wigfield et al. 2006). Variables considered in studies of teacher support include trust, closeness versus conflict, and others (Birch and Ladd 1998; Resnick et al., 1997). Unfortunately, as with many other aspects of the school experience that may impact on well-being, teacher-pupil relationships tend to decline once the pupil progresses to secondary school (e.g., Wentzel, 2002). This is especially the case for pupils with little intrinsic motivation to learn (Pianta, 2006).

During the primary school years, children typically have extended contact with a single teacher or small number of teachers, who may therefore become very salient elements of their interpersonal field. In secondary school years, children may or may not establish meaningful personal contact with their teachers, depending upon the structure of the school, teacher and pupil attitudes, time and other factors. In the study by Rutter and colleagues (1979), teacher availability for personal contact was associated with several positive indices of school outcome, though these were more academic than social. Some more recent data also indicated that the benefits of personal contact may not be that clearcut. Kasen, Johnson and Cohen (1990) interviewed 300 New York pupils aged 16 years to obtain descriptions of the climate of the 250 schools they attended. Their parents were interviewed regarding the participants' problem behaviors; these interviews were repeated 2 years later. Contrary to expectations, children attending schools rated as high in social facilitation (i.e. where teachers arrange personal discussions) displayed greater increases in depression and anxiety, though no change in conduct problems or oppositionality. These results suggest that the effects of personal teacher- pupil contact vary according to the general level of hostility and conflict in the environment. In schools 
characterized by high levels of conflict, discussions about interpersonal problems may provide an opportunity to express feelings, but not eliminate the hostility in the environment nor mitigate its effects. In any case, it is important to remember that the specific effects of these personal contacts on children's social competence were not explored in either of these two interesting studies.

Teacher feedback to pupils. White, Smith and Kuzma (1991) conducted an interesting study in which children were shown videotapes of teacher-child interaction. Different versions of the videotape displayed different amounts of positive and negative teacher feedback. Positive teacher feedback did influence the subject's ratings of liking of the child actors to some extent; negative teacher feedback influenced the ratings more heavily. In consecutive studies, White and colleagues continue providing results which confirm the effect of teacher feedback on children' s evaluations of a target child, and this independently of the kind of teacher feedback and the reputation of the target child (White et al. 1996; White and Jones 2000). White and Jones (2000) illustrate the importance of considering nonevaluative teacher attention in combination with children's reputational status, especially in the case of children with positive reputation.

Flanders and Havumaki (1960) conducted an interesting analogue study of the effects of praise on peer perceptions of liking. In discussion groups formed for the purpose of the study, half the previously unacquainted adolescent participants were praised by the adult group leader for their contributions. Those who had been praised received higher sociometric ratings of popularity from other group participants. A small-sample study by Medinnus (1962) provides some confirmation that, in a real classroom, teacher praise is linked to patterns of peer liking. The sociometric status of the 6-yearolds studied was highly correlated with both frequency of teacher praise and teachers' ratings of their preferences among pupils.

Feshbach (1967; Portugues and Feshbach 1972) conducted a series of studies in which primary 
schoolchildren were shown films of either rewarding, positive teachers or hostile, negative ones. Following the films, the children's imitation of the modelled behaviors was observed. Many of the children imitated the behaviors of the positive model, though some important social class differences were noted. The tendency to imitate positive teacher behaviors may be limited to middle-class subjects, and not extend to lower-class schools, where, unfortunately, critical authority figures may be more familiar to the children. Thus, Feshbach's results depart somewhat from the general pattern of research findings, which clearly indicates that teacher enthusiasm is associated with positive student outcome.

There has also been some suggestion that certain types of children react more favorably to teacher input. Byrnes (1985) discussed this in connection with the specfic needs of socially neglected children, who are not actively rejected by peers, but forgotten and isolated. Research is needed to corroborate her observation that these pupils are in particular need of individual teacher attention, an assertion which intuitively seems quite valid.

Furthermore, it may be more profitable to assess teacher praise and encouragement in vivo rather than use either Feshbach's videotaped or White's analogue technique or Flanders and Havumaki's somewhat contrived group discussion task.

Teachers' optimism and confidence. By subjecting his intriguing theoretical views to systematic empirical research, Carl Rogers succeeded in convincing a generation of psychologists that warmth, empathy and unconditional positive regard are "core conditions" which facilitate interpersonal relationships. Rogers's theory (1959) had profound impact on education. Most studies indicated that in a more student-centered learning environment, the learners' self-concept is enhanced, while academic progress is, at the least, not decelerated in comparison to a content-centered setting.

Teachers' beliefs about their pupils often come true, according to pertinent theory and research. As well, teachers' beliefs about their own abilities and their own effectiveness are increasingly cited as 
important determinants of school success (Beard et al. 2010). Wigfield and colleagues (2006) describe a vicious circle in which the teacher`s lack of confidence in his or her own abilities translates into a lack of confidence in the abilities of the pupils, leading to alienation and failure on their part. On the other hand, when teachers believe in their pupils' capacities, pupils feel more connected to the school experience and are less likely to display conduct problems (Brophy 2004; Hattie 2009).

Teacher's leadership style and organization of the classroom. Believing in pupils, relating warmly and well with them and supporting them need not come at the expense of discipline and order. In the influential inner-London studies of pupil adjustment in middle schools (Mortimore 1998), organization and proper management of time emerged as strong correlates of adjustment. There is very clear support in research, first of all, for the need for clear routines and standards for pupil behavior. This improves both achievement and pupil behavior. At this same time, order is not inconsistent with the granting of appropriate autonomy to pupils (Eccles and Roeser, 2003; Grolnick et al. 2002).

Organization of academic content may also be related to motivation and well-being. Pupils learn more, behave better and are more connected to the academic experience when it provides an appropriate level of challenge and seems relevant to their future needs (Finn 1989, 2006; Graham and Taylor 2002). Vygotsky's concept of scaffolding suggests an ideal sequencing of ideas and demands on the learner, which has been found to promote interest, achievement and motivation (Wigfield et al. 2006).

School climate. The school climate is a multidimensional construct with numerous connections and implications. We have considered those aspects that are not included in the previous paragraphs: the normative component that regulates the appropriate behaviors, supportive relationships between teacher-student and between teachers, and the atmosphere or moral climate of the school. 
School behavioral climate. In schools where principal and teaching staff set rules on appropriate behavior and efficient procedures of monitoring students' progress, achievement increases while disruptive and antisocial behaviors lessen. Connell and Wellborn (1991) state that providing orderly throughout the whole school a predictable and methodical behavioral structure, defined by the presence of clear and fair norms and expectations, judicious use of reinforcement, informative feedback and consistent standards of implementation, helps to increase the students' autonomy, because it provides them with information on how to be competent and successful in that environment.

Supportive relationships. A supportive relationship between teachers and students, as well as among teachers, is another critical element in the social system of the school. In fact the focus of every school reform is to promote relationships that stimulate and make students feel engaged, and simultaneously transmit support to teachers (Connell 2003).

The pedagogical caring proposed by Wentzel (1997) (i.e. the perception that teachers care about what one is learning as a student) is a critical aspect of the school social climate. The perception of the social support provided by teachers and the sense of belonging and being a member of a broader community are important precursors of motivation to learn (Wentzel 2009), this perception is especially critical in the case of children and young people who belong to ethnic, racial or language minority and low socioeconomic status (Garcia-Reid et al.2005).

Likewise, in the reform called "First-Things-First," the first issue that was addressed in order to prepare the reform was to cultivate positive relationships among the teachers of a school. Creating conditions leading to the well-being and development of teachers is essential for the motivation and ability of these teachers to create in turn the same conditions for their students (Sarason 1990). 
The cohesiveness of the school's teaching staff may be communicated to the pupils in both obvious and subtle ways. Regardless of what advice teachers may give children about the proper ways of interacting, the adult interactions observed may constitute a highly salient instructional medium. In Rutter and colleagues (1979) study of secondary schools in Inner London, staff relations emerged as a powerful predictor of several types of school outcome (though peer-related social competence was not measured specifically in that study).

At least one ethnographic study confirmed that co-operative interactions among the school staff do have some connection with children's peer relations. Batten and Girling-Butcher (1981) used a combination of interview techniques and rating scales to compare the quality of seven Australian secondary schools. In one of the seven, a Catholic religious school, the staff were seen by the pupils as working together like a family and displaying a keen sense of commitment toward each other. In that school, peers were seen as particularly friendly and supportive. The students interviewed spoke of one particular case in which a classmate who had experienced marked difficulty getting along with others in a previous school was learning to adapt well in this more cohesive environment.

Two lines of research can be used to see the effects of school culture in educational reforms: Accelerated Schools Project (ASP) (Levin 1998) and interventions that try to apply the lessons learned from studies on school effectiveness in order to help schools in crisis(Hopkins and Reynolds 2001).

School moral climate (atmosphere). It refers to issues such as how fair and impartial are the norms, whether principal and teachers believe or not that it is possible to promote learning and development of all students, the type of modelling provided by teachers, whether students have say in school matters and can participate in making decisions about learning and other issues . 
Schools as fair communities, like Kohlberg (1970) proposed, are a pioneering vision that emphasizes a global orientation of the school in which students learn democracy and ethical reasoning. Child Development Project (CDP) in Oakland, California, has been carrying out such a work to promote the moral climate of the school. They encourage the students to take part in cooperative activities and serve the community at school level. Such practices help to achieve a "community of care", and influence positively to a proper behavior at school, feelings of belonging, motivational beliefs and self-concept (Schaps 2003)

Goal structure. The goal structure guides both the activity in school and classroom and the value that is given to results and academic performance.. The way to achieve these results can be competitive or cooperative. A particular modality of cooperation is peer tutoring.

Goal structure. One of the most important components of the school culture is the goal orientation of the school. Maehr and Midgley (1996) argued that there were at least two academic goal structures: performance-oriented, where academic success is defined in terms of showing higher capacity and achieving higher grades, and mastery-oriented, where academic success is defined in terms of the student's efforts to master the content, improve skills and learn by means of trial-and-error approaches, and social support.

Students who perceive their school as mastery-oriented adopt the same orientation, which in turn influences their beliefs of self-efficacy and their positive affect toward the school (Roeser et al.2006); they consider the school to be more positive and their emotional stress decreases (Roeser et al.1998a); they have a greater perception of well being and realize fewer disruptive behaviors (Kaplan and Maehr 1999); they report higher levels of attachment to school (FiqueiraMcDonough 1986). In a review of the 25 years of the Achievement-Goal Theory, Meece and colleagues (2005) concluded that " whereas schools environments that are focused on 
demonstrating high ability and competing for grades can increase the academic performance of some students, research suggests that many young people experience diminished motivation under these conditions" (p. 487).

The literature has reported that during the transition from primary to secondary, both teachers and students perceive a greater emphasis on performance-oriented goals (Maehr and Midgley 1996; Roeser et al. 2002). The students who perceive this most weight in achievement show higher levels of extrinsic motivation and academic anxiety, and qualify the academic performance as more important to assess the academic success than those students who do not have this perception of their school environment.

Cooperative vs. competitive goal structures. The promotion of cooperative learning experiences has been probably the most active and best-accepted effort to date at restructuring the social ecology of the school. Co-operative learning techniques were developed as an alternative to the competitive goal structure of most schools. A system in which pupils compete with each other for marks allows no incentive for children helping each other: helping another child is usually considered cheating. Where there are official or unofficial restrictions on the proportion of high marks which can be assigned, a student who provides assistance to classmates may lower her own mark as a result (Johnson and Johnson 1975; Slavin 1987). Thomas (1984) maintained that competitive goal structures have replaced harsh discipline as a tool used by urban schools to maintain a modicum of control over pupils. In his view, competition is no more productive a tool in the long run. It causes profound alienation of disadvantaged youth, who escape the situation by not achieving their potential and by leaving school early.

Proponents of cooperative learning have developed a variety or specific procedures and empirically documented their effects. According to Kagan and Kagan, (2009) "Cooperative learning 
has perhaps the strongest empirical research base of any educational innovation" (p. 1.5)

Cooperative learning does not mean simply telling children to work together. In order for cooperative goal structures to meaningfully influence the social system, it is necessary to create a positive interdependence, where incentives must be made contingent on group rather than on individual achievement and tasks are so structured that they cannot be done individually. Individual accountability must also be built in if the pupils are to take the co-operative learning experience seriously (Slavin 1987). One important challenge in modifying the competitive goal structure of the traditional school is to provide each child or group with an equal participation, an equal opportunity to succeed and obtain rewards. According to Kagan (1999), these principles or elements of cooperative learning are further enhanced by means of increasing the students' participation, which occurs when the sequential interaction present in the competitive classes, one student at a time, is replaced by the simultaneous interaction, i.e. more students participate and learn simultaneously.

Johnson and Johnson (1975) organized children into work teams and pupils are considered as teammates. The "jigsaw classroom" (Aronson et. al. 1978) is another innovation designed to promote co-operative goal structure. More recently, Kagan (1999; Kagan and Kagan 2009) have proposed uncomplicated structures of cooperative learning. Structures are like tools in the teacher's toolbox, which will help to organize the teaching, learning and living together in the classroom. Each structure is a sequence of steps describing how teachers and students interact with the curriculum; it can be applied repeatedly to different content, and of course it implements the cooperative principles. These structures develop automatisms, some efficient and some not so much, and foster learning and engagement, some in less extent and in less students and some more extensively and in more students. 
While there has been a great deal of research on the effects of these cooperative learning experiences, cognitive outcome measures have been far more prevalent than measures of social competence. Thorough reviews of this literature were presented by Johnson and Johnson (1975), Johnson et. al. (1981) and Slavin (1987). The majority of findings indicate that children achieve greater academic gain in co-operative learning experiences than in control conditions of various types. This optimistic picture has been challenged because of the methods used both in the reviews and some of the original studies (Vedder 1985) and because co-operative learning experiments may be more successful in that culture than elsewhere (Madsen and Shapira 1970).

Roseth, Johnson and Johnson (2008) conducted a meta-analysis on the effects of goal structures in a sample of 17000 adolescents, in which they concluded that higher achievement and more positive peer relationships have a higher correlation with cooperative goal structures than with the other two goal structures, the competitive and individualistic ones. Cooperative learning is well received because it is at present the only educational innovation that gives some responses to the most important crises or challenges facing education (Kagan and Kagan 2009): The achievement crisis; the crisis of the imbalance between those who learn a lot and those who learn less; the immigration crisis, and the crisis of social competence. The benefits of cooperative learning extend to all students, especially to students with special educational needs.

Peer tutoring. Another way of integrating positive peer experience with academic content is having more capable children assist their classmates who are in academic difficulty. Pigott, Fantuzzo and Clement (1986) arranged peer tutoring for primary school pupils weak in arithmetic. They found that this procedure resulted in improved arithmetic achievement. As well, there were dramatic gains in the peers' ratings of the social acceptance of the study team members. In a series of studies, Strain and his colleagues (Strain 1985) instructed non-handicapped classmates to prompt mentally handicapped 
peers in such appropriate social behaviors as initiating play or conversation, sharing toys, helping others and expressing affection. Results showed dramatic increases in the prompted behaviors. While research overwhelmingly has documented the effects of peer tutoring on academic achievement, its benefits for children's peer relations have not been established as clearly, though they are depicted graphically in many qualitative accounts (Goodland and Hirst 1989).

School student body intake mix. This section approaches the issue of initial differences between schools. These differences may be caused by the type of students that attend the school (students' age and gender, educational needs, ...), by the availability of economic and personal resources, or by the decisions of the school in how to group its students.

Age and gender composition of the student body. The age range and gender distribution of pupils in a school may both contribute to the social relations of students. A wide range may provide for modelling by older children. When students remain in the same school for a longer time period, groups may be more cohesive than where promotion to higher forms or grades leads to transfer to a new and inevitably larger school. There has been little systematic study of these effects for primary or secondary school pupils.

Heterogeneity in the initial characteristics of student body. Another feature of the school context is the mix of socially disadvantaged students with students with more resources, of students with significant emotional or behavioral problems mixed with students who do not have any problem. This mix within the school student body has been associated with the educational outcomes of the students (Rutter and Maughan 2002). As the ratio of socially disadvantaged students goes up in a school, its aggregate achievement decreases (Rumberger and Palardy 2005).LeBlanc and colleagues (2007) found that the proportion of students with disruptive behavior in elementary schools predicted subsequent rates of behavioral problems in secondary 
schools. In general, individuals feel best in those school settings in which they fit well with the norms and aggregate features of the student body (Eccles and Roeser 2011).

According to Rutter and Maughan (2002) the key question is how these effects are mediated, particularly whether contextual influences operate mainly through the running of the school (organization and educational practices, for example), through the peer processes (peer culture, for example), or the comparison processes among individuals (self-esteem, for example). Their conclusion is that the three mechanisms are present and further research is required. The issue is far from resolved. The situation is not very different from the academic arguments about streaming or tracking which will be addressed later on, and those about ordinary integration schools and about special schools for children with special needs (Howlin 2002).

Resources and disadvantaged schools. A closely related issue to the one just discussed refers to the human and economic resources that a school receives. Despite the accepted belief that more money produces more school success, the effect of the level of school resources on students' progress continues to cause controversy (Greenwald et al.1996). Studies on school effectiveness have generally found a weak link between school budget and students' performances, and the question raised by Coleman (1968) about how many financial resources are needed to increase the students' performance or to reduce the inequality among students, still remains unsolved.

Gershoff and Aber (2006) define the Disadvantaged Schools by the lack of resources they receive. One indicator of a Disadvantaged School is the percentage of students entitled to a dining support or grant. Schools with a higher proportion of these students achieve lower grades, these students report less positive attitudes toward school, and parents of pupils of high-poverty schools are less likely to participate in school activities (Wirt et al. 2003). Negative results 
extend to all the children attending schools with more than half of the pupils entitled to grants, regardless of the fact that the target child himself need a grant (Mayer et al. 2000). These schools suffer from a continued deterioration (NCES 2000).

There are certain contextual features that are common to low-income schools that make them become places that discourage learning: 1) the higher proportion of low-qualified teachers, 2) the proportion of teachers who move each year to another school is much higher, 3) the higher proportion of inexperienced teachers, 4) lower wages, 5) teachers are more likely to exercise greater control over students because they believe that the students of these schools lack of the self control needed to motivate and regulate their own learning, 6) these schools often increase in size and class ratios in order to increase their resources. Thus, the economic resources of a school clearly establish its human resources and these may determine the quality of teaching and the learning outcomes. Students in those schools learn less and behave worse than those in schools with well-trained teachers.

The economic resources are also relevant to the physical ecology of the school, namely, through the school physical appearance. Schools with high concentrations of poor students are equipped with more metal detectors, more bars on the windows and there are more graffiti on the walls than in richer schools. What kind of message does this fact transmit to students in terms of safety, belonging and identification with the school? The "Broken Windows" theory on delinquency and crime (Wilson and Kelling 1982), argues that, for instance, physically abandoned or poorly maintained spaces carry a message of absence of ownership and lack of moral structure, and thus these spaces become melting pots of anti-social activity (Gladwell 2000).

Grouping students by academic ability. Kagan (1990) discussed a number of ways in which 
schools help or alienate children who are at risk for psychological difficulty. These include isolating them to sub-groups which, in the opinion of some, do not identify with the school and with the process of learning. Indeed, it has been shown that once students within a classroom have been grouped on the basis of academic ability, social boundaries form and are rarely crossed (Putallaz and Gottman 1981; Ready and Lee 2008), though the increased contact with individuals within one's own track may facilitate friendship formation within it (Hansell and Karweit 1983). Since individuals' academic and social competence tend to correlate, ability grouping (tracking) may lead to differential access to competent peer models as well as differential peer reinforcement of social skills. However, in mixed-ability groups or classes, high academic achievement may serve as the ticket to group participation and peer acceptance (Asher et al. 1977).

The tracking, or curricular differentiation based on different levels of ability, organizes the students' experience and behaviors in three directions (Roeser et al. 2009): a) the quality and types of learning opportunities it offers (Oakes 2005), b) it determines the exposure to different peers, and somehow the nature of the social relationships that form in the school (Dishion et al. 2001), c) it determines the social comparison group that the students will use to assess their own abilities and develop their academic identities (Marsh et al. 2008).

There is no established consensus on the overall effects of curriculum diversity or tracking (Eccles and Roeser 2011; Hattie 2009). But the results are not encouraging in any of the three directions. Current studies indicate that students who are assigned to high tracks accelerate their development, but their self-concept decreases, while those assigned to low track slow their progress, but their self-concept increases. Unfortunately, the low tracks schooled students are labeled by their peers and teachers as dumb (Frank et al. 2008). In addition, as students have more relationships with the peers with whom they spend more time, this situation can lead low 
tracks students to engage in risk or criminal activity (Dishion et al. 2001). Students tend to stay in those tracks where they had initially been schooled (Lucas 1999).On the other hand, tracking can maximize the likelihood that pupils will encounter academic content that is relevant to them. Highability pupils may find support and stimulation when grouped with peers who share their abilities and interests (Lando and Schneider 1997). Thus, tracking seems to bring both positive and negative results (Roeser et al. 2009).

Recreation time and extracurricular activities. Developmental theorists such as Piaget emphasized that play is an important facilitator of cognitive development. School recreation periods provide opportunities for exploration, manipulation of objects, practice of social skills and stress reduction (Ramstetter et al. 2010). As well, extracurricular activities and recreation are essential for the physical well-being of children and for the formation and consolidation of interpersonal relationships. This should by no means be considered growth that occurs at the expense of academics. In fact, it has been found that participation in extracurricular activities is actually correlated positively with the mastery of academic content (Eccles and Roeser 2011; Lagacé-Séguin and Case 2010; Powell et al. 2002). Furthermore, pupils who participate in extracurricular activities report a strong school engagement and high educational aspirations (Eccles et al. 2003) and higher levels of life satisfaction than do other pupils (Gilman et al. 2004). Pupils who elect not to participate in extracurricular activities tend disproportionately to drop out of school (Mahoney and Cairns 1997). Unfortunately, many schools fail to provide recreation or recess for their pupils, thus triggering off a lively debate on this matter (Lagacé-Séguin and Case 2010).

Eccles and Templeton (2002) suggested that the benefits associated with participation in extracurricular activities occur through the following mechanisms: increased relationships with peers more academically oriented, more time accompanied by adults who provide support and 
good mentoring, increased opportunities for building up social networks and for practicing necessary skills leading to success in school.

This is an important point to take into account, because schools differ in the amount and type of extracurricular activities, and in the recess periods that they offer to their students, especially those schools which have few resources and are very large.

\section{Empirical Support for the Importance of Schools}

\section{Global empirical evidence to date}

Large-sample correlational data and meta-analysis. Early thinking was heavily influences by data indicating that the statistical size of school effect is small in a statistical sense. For instance, the classic Coleman report (Coleman et al. 1966), indicated that somewhere between 10 and 14 percent of variation in pupil achievement could be accounted for by school effects, but these percentages should be reduced by over $50 \%$ in order to account for differences among the schools in demographic factors such as parental education and income, yielding in some cases, an adjusted estimate of $5 \%$ of the variance. These data led to a rather pessimistic view of the importance of schools. Other major studies of the era yielded very similar estimates.

Beginning in the 1970s, meta-analysis emerged as result of increasing pressure by policy makers for valid syntheses of research on important issues (Light and Pillemer 1984). Schooleffects research were an important issue on which a great many of studies had been conducted, indicating the need for sophisticated strategies for research synthesis. However, it is important to note the limitations of meta-analysis in the synthesis of school-effects studies. The most important of these limitations is the averaging across highly diverse independent measures of school features and highly diverse outcome measures. 
Although a myriad of studies and syntheses of their results yield the same conclusion, it should be noted that this literature is difficult to synthesize. All outcomes - academic, behavioral, vocational and personal - tend to be averaged together. Therefore, potentially interesting differences across outcomes may not be represented adequately in syntheses of school-effects research. Bosker and Scheerens (1989) advocate more standardized reporting of research results, including clearer specification of individual effect sizes.

Importantly, when these small (but potentially important) effects are analyzed together with more powerful influences such as family factors and neighborhood risk, the school influences may be obscured. This occurred, for example, in the results of a sophisticated survey conducted in the U.K. on family, neighborhood and school influences on different aspects of pupil well-being, in which school factors were found to be non-significant (Bradshaw et al.2011).

One sophisticated estimate of the extent of school effects was provided in a meta-analysis by Bosker and his colleagues, who considered 89 studies from several countries, yielding a net effect size of .30 of a standard deviation unit, but because of a number of factors that should be taken into consideration, may really be no higher than .20 . One of these factors is that part of the effect may not pertain to the influences of schools but to the influences of classrooms. In interpreting the data, they remind the reader that many of the effectiveness statistics may represent little more than snapshots in time that portray effects that may not be stable. Averaging across studies may also obscure differential effectiveness of schools at different ages.

Although this meta-analysis yielded revised estimates of school effects on school achievement that were somewhat higher than those in the Coleman report, Scheerens and Bosker provide the most salient reason for still believing in school effects - and working to enhance 
them - despite effect sizes that are somewhat modest. They note that schools do not affect all of their pupils to an equal extent. Schools are likely to be most effective for pupils who come from disadvantaged or deprived backgrounds. Although the meta-analysis is focused on academic achievement, there is no reason to believe that school effects are any larger for psychosocial data.

Studies on school effects have burgeoned in the intervening decades. Many of the recent studies were designed with efforts at correcting the limitations of earlier ones, although many problems remain. Kyriakedes and colleagues (2010) conducted a meta-analysis of 67 studies conducted in various parts of the world between 1990 and 2010. In contrast with earlier metaanalyses and qualitative research syntheses, these authors adopted a multi-level theory-driven approach. Their dynamic model is based on the assumption that various school-level factors influence classroom-level practice, especially the behavior of teachers. School-level policies are of course influenced by the broader cultural context and national educational policies. They see these cultural and school factors as shaping classroom -level factors, such as interacting with such individual pupil-level factors as socio-economic status, gender, culture and personality in determining cognitive and affective outcomes alike. The meta-analysis revealed support for the most fundamental pathways specified in the model, with small but significant correlations mostly averaging about .15 across studies.

Thus, the rapidly accumulating data indicate quite clearly that schools do have effects of various kinds on different aspects of the well-being of their students, although these effects are not usually large in the statistical sense. Despite the modest effect sizes, these influences are widely considered much more important than they once were thought to be. One of the main reasons for this is the emergence of better general understanding of the real-life importance of 
small effects. Small effects may be very consequential for certain individuals, especially individuals at risk for failure, even if the influence of schools, for example, across the entire population, is not very large (Light and Pillemer 1984).

\section{Outlier studies}

Another approach to gauging the "true" effects of schools is the analysis of outlier studies. This entails isolating data from schools with effectiveness data far higher than those of most others schools. Purkey and Smith (1983) conducted an influential report on seven case studies of outlier schools. The results indicated the following features of outstanding schools: strong leadership; orderly climate; high expectations; frequent evaluation of students; emphasis on pupil achievement; cooperative atmosphere; clear academic goals in all subject areas; good training of staff, and an emphasis on being on-task. Essentially the same dimensions were identified in a well-known influential narrative review of school effects by Mortimore (1998). Reviewing data from many countries on these issues, Scheerens and Bosker conclude that there are many problems in generalizing internationally the dimensions identified by Purkey and Smith.

\section{Methodological issues}

The interpretation of the burgeoning literature on school effects is a challenging enterprise because of the many methodological issues that arise in designing good research in this area. One fundamental concern, ignored in many published studies, is that school effects occur at different levels. If this is not taken into account, what might be understood as a school effect - or lack of effect - may be confounded with what is really a teacher effect or classroom effect, on the one hand, or with a community or cultural effect on the other. Statistical advances, such as multi-level modeling are being used 
increasingly to separate these different effects (Luyten and Sammons 2010). Some critics of studies conducted before the advent of widespread multi-level modeling contend that teacher effects are in fact larger than school effects in general (Hill and Rowe 1996; Teddlie and Reynolds 2000).

Other fundamental methodological issues include the choice of both the independent and dependent variables and how they are measured. In this area of research, much more attention has been paid to outcome measures, such as pupil achievement, than to measuring the school factors that might be related to it. Although many theorists in the field emphasize that pupil outcome should be the focus of school-effects research (Bosker and Scheerens, 1989), this does not mean that methodological issues in the measurement of the school process linked with outcome should be totally ignored.

A complete critique of issues in the measurement of pupil outcome is beyond the scope of this essay. However, it is worth noting that much more attention has been devoted to measurement issues regarding academic achievement than to measurement of the many other valuable outcomes, including many of the indicators of well-being that have been discussed in this essay and in other chapters of this book. Related to this is the question of whether researchers can or should be content with intermediate measures of both independent and dependent measures. Statistics about the attainment of specific school levels, graduation rates, etc., are easily obtained but may not fully represent the school reality that a researcher wishes to study (Bosker and Scheerens 1989). In their very famous study of the effectiveness of schools in the economically deprived neighborhoods of central London, Rutter and colleagues (1979) went so far as to use the presence of potted plants in the classroom as an indication of the teacher's attitude towards the 
physical setting. This, of course, may not fully satisfy the specifications of all theorists and methodologists.

Mortimore (1998) emphasized judging schools on the basis of their improvement over time, not their effectiveness at any particular moment. This issue is particularly pertinent to schools that are known to underachieve and to schools enrolling large numbers of disadvantaged pupils. He also advocated focus on the school culture as a central element of effectiveness research. Mortimore insists that the school culture must be positive, with learning valued for its own sake and with mutual trust among the people of the school.

It has long been known that school effects can easily be confounded with the personal, community and cultural resources brought to schools by their pupils. Influential studies, even those from as early as the 1960s, included careful measure of intake factors such as family income, parental education, I.Q., etc. However, and quite surprisingly, this issue is sometimes ignored (Purkey and Smith 1984; Bosker and Scheerens 1989). The confounding of school effects with those of the neighborhoods in which the schools are located occurs, most obviously, in places where children from the same neighborhood attend the same schools. In a recent Canadian study involving over 1,400 youth, Oberle, et al. (2011) found a small but significant positive correlation between school factors and perceived neighborhood support. However, their analysis revealed that the school factors still contributed significantly to adolescent life satisfaction over and above the statistical prediction accounted for by the neighborhood factors (see discussion of multi-level modeling below). Importantly, an optimistic attitude by the pupils was also linked to life satisfaction, over and above the variance explained by school, neighborhood and family contexts. 
One classic challenge is the reality that, in most countries, most schools resemble each other in many if not most relevant respects (Rutter 1983). All correlation statistics are attenuated by restricted range. Therefore, it is important to analyze specifically the outlier schools, as discussed above, that provide either markedly excellent or markedly deficient educational environments (Bosker and Scheerens 1989).

A final and very consequential methodological challenge is to analyze the stability of any school effects over time, across classrooms within schools, and across different outcome criteria (e.g., academic, social, behavioral, attitudinal). Demonstrating stability in these respects invokes important issues in the design of longitudinal research, including attention to issues of attrition and missing data. Longitudinal methods can be applied to long-term benefits to individual pupils as well as to long-term effects of individual schools on successive cohorts of pupils (Bosker and Scheerens 1989).

\section{Interventions to Promote Well-Being at School}

The multiple ways by which schools can influence the well-being of their students suggest a myriad of possible interventions that can conceivably promote well-being at school. Accordingly, improving the quality of schools in many different ways could bring benefits to pupil well-being. An exhaustive list of possible interventions is not possible here.

One approach, documented in several recent writings, is to explore with the pupils of a specific school the most important obstacles to well-being they perceive in their school environment. Conceivably, teachers, parents and other members of the broader school community could be involved in this type of process. However, advocates frame 
this intervention approach within the framework of recognizing children's voice consulting with children about decisions that pertain to their lives, even allowing them to reach certain decisions as appropriate (Hall 2010). Hall, an educational psychologist in the U.K., conducted focus-group interviews the pupils of various grade levels at a single school. During their interviews, the pupils articulated the obstacles to well-being at school that most irritated them. Under the guidance of the psychologists involved, they then developed an action plan for promoting well-being. The action plan included concrete measures to improve the cleanliness of the lunchroom, increased use of praise and positive reinforcement by the teachers, "worry boxes" in which children could deposit messages expressing aspects of their school experience that they dislike, and more frequent outings especially nature-discovery trips.

At times, this approach may lead to the discovery of more substantial obstacles to well-being than are contemplated by the school personnel who initiate forays into the subjective perceptions of pupils. This occurred, for example, in another project conducted in the U.K. by Duckett and colleagues (2010). Their methodology included interviews with pupils, pupil expression by means of journal diaries covering a one-week period, and talks about the school. The resounding conclusion was that the only meaningful way of improving pupil well-being at the school was to find some way to deal with the pervasive and insidious bullying that was going on virtually unchecked. Unfortunately, the school authorities tried to prevent release of the report generated by this project team.

Another strategy for determining the areas in which to intervene is to attempt to define the educational needs of individual pupils rather than the shortcomings of schools. These needs may fall in many areas, including academic, social and personal skills. 
Carmen et al. (2011) implemented this approach successfully with a small number of atrisk early adolescents in Melbourne, Australia. Obviously, such customization involves considerable expenditure of energy and time.

\section{Concluding Remarks}

The central theme of this essay is that schools make a difference in children's well-being despite any remaining vestiges of the belief that schools have only minimal impact on the pupils they serve and who spend much of their developing years in them. It is interesting from an intellectual standpoint to debate the relative importance of the influences of schools, families, peers, communities and cultures. However, in real terms, this debate loses its fire after one recognizes that schools do have clear effects. For one thing, it is very probable that in most cases, schools replicate rather than contradict the socialization practices of the other agents of socialization. Thus, schools probably do not compete with other sources of guidance. Furthermore, there may well be situations where a teacher, school official, school peer group or school athletic coach can have a substantial positive impact on a growing child who experiences unfavorable conditions in other contexts. This is not to say that schools can substitute for nurturing authoritative families or for equitable, just societies.

As discussed in the first few pages of this essay, some educationalists, such as Noddings, have argued for specific school curricula aimed at promoting the well-being of children and adolescents. Although we do not disagree with Noddings' suggestion in any way, we are not certain that the promotion of well-being depends entirely on add-ons to the curriculum. As we have enumerated herein, schools promote well-being in a myriad 
of ways that are embodied in their very structure and in the interpersonal exchanges that emerge throughout the school days and years.

Undoubtedly, enhancing well-being by improving schools means, to some extent, investing more public resources in schools. However, there is only a very small correlation between the money spent in schools and their quality (Greenwald et al. 1996). More important is the way in which those in charge of school go about their work in stimulating interest, relating to children, organizing the school, and, not by any means the least of their tasks, teaching academic content.

\section{References}

Adalbjarnardottir, S. (1991). How children negotiate with classmates and teachers: Development in thought, action, and style. Paper presented at the biennial meeting of the Society for Research in Child Development, Seattle, WA, April 1991.

Adamson, P. (2007). Child poverty in perspective: an overview of child well-being in rich countries. Innocenti Report Card 7, UNICEF Innocenti Research Centre, Florence.

Addington, L. A., Ruddy, S. A., Miller, A. K., \& DeVoe, J. E. (2002). Are American's schools safe? Students speak out: 1999 school crime supplement (NCES 2002 - 331). Washington, DC: National Center for Education Statistics, U.S. Departament os Education. Retrieved January 7, 2004, from http://nces.ed.gov/pubs2002/2002331_1.pdf

Allardt, E. (1989). An updated indicator system: Having, loving, being (Working papers 48). Helsinki, Finland: Department of Sociology, University of Helsinki.

Alvarez-Valdivia, I., Lorenzo-Chavez, K., Schneider, B.H., Roberts, J., Becali-Puerta, B., PérezLujàn, D., \& Sanz-Martinez, Y. (in press). Parental involvement and the academic achievement and social functioning of Cuban schoolchildren. School Psychology International.

Amabile, T. M. (1983). The social psychology of creativity. New York: Springer-Verlag.

Anderson, C. S. (I982). The search for school climate: A review of the research, Review of Educational Research, 52, 368-420.

Andriessen, I., Phalet, K., \& Lens, W. (2006). Future goal setting, task motivation and learning of minority and non-minority students in Dutch schools. British Journal of Educational Psychology, 76, 827-850.

Argyle, M. (1987). Psychology of Happiness. London: Methuen.

Armstrong L. Online on webpage A History of Jazz (http://www.historyjazz.com/jazzstyles.html , accessed 8 August 2011). 
Aronson, E., Blaney, N., Stephan, C, Sikes, J., \& Snapp, M. (1978). The jigsaw classroom. Beverly Hills, CA: Sage.

Asher, S. R. (1985). An evolving paradigm in social skills training research with children. In B. H. Schneider, K. Rubin, \& J. E. Ledingham (Eds.), Children's peer relations: Issues in assessment and intervention (pp. 157-174). New York: Springer-Verlag.

Asher, S. R., Oden, S. L., \& Gottman, J. M. (1977). Children's friendships in school settings. In L. G. Katz (Ed.), Current topics in early childhood education (vol. 1, pp. 33-61). Norwood, NJ: Ablex.

Astor, R. A. (1998). Moral reasoning about school violence: Informational assumptions about harm within school subcontexts. Educational Psychology, 33, $207-221$.

Bagwell , C. \& Schmidt, M.E. (2011). Friendships in childhood and adolescence . New York : Guilford Press Publisher.

Barker, R. G., \& Gump, P. V. (1964). Big school, small school. Stanford, CA: Stanford University Press.

Barr, D. (1997). Friendship and belonging. In R. L. Selman, C. L.Watts, and L. (Eds.), Fostering friendship: pair therapy for treatment and prevention (pp.19-31). New York: Aldine de Gruyter.

Batten, M., \& Girling-Butcher. S. (1981). Perceptions of the quality of school life (ACER Research Monograph no. 13), Hawthorn. Australia: Australian Council for Educational Research.

Battistich, V., Solomon, D., Watson, M., \& Schaps, E. (1997). Caring school communities. Educational Psychologist, 32, 137-151.

Battistich, V., Watson, M., Solomon, D., Lewis, C., \& Schaps, E. (1999). Beyond the three R's: A Broader agenda for school reform. Elementary School Journal, 99, 415-432.

Beard, K.S., Hoy, W.K., \& Woolfolk Hoy, A. (2010) Academic optimism of individual teachers: Confirming a new construct. Teaching and teacher Education, 26, 1136 - 1144.

Beelman, A., Pfingsten, U., \& Losel, F. (1994). Effects of training social competence in children: A meta-analysis of recent evaluation studies. Journal of Clinical Child Psychology, 23, 260271.

Ben-Arieh, A. (2009). Indicator of children well-being: trends, status and perspectives for the future, in The on-going debate on the assessment of children's conditions of life. Florence: UNICEF Innocenti Research Centre.

Ben-Arieh, A., McDonell, J., Attar-Schwartz, S. (2009). Safety and home-school relations as indicators of children well-being: Whose perspective counts? Social Indicators Research, 90, 339-349.

Bennett, N. (1998). Annotation: class size and the quality of educational outcomes. Journal of Child Psychology and Psychiatry, 39, 797-804.

Berg, Y., Segers, E., \& Cillessen, A. (2011). Changing Peer Perceptions and Victimization through Classroom Arrangements: A Field Experiment. Journal of Abnormal Child Psychology, (Preprints), 1-10. 
Berndt, T.J. (1999). Friends' influence on students' adjustment to school. Educational Psychologist, 34, 15-29.

Berndt, T. J., \& Bulleit, T. K (1985), Effects of sibling relationships on preschoolers' behavior at home and school. Developmental Psychology, 21, 761-767.

Berndt, T. J., \& Keefe, K. (1995). Friends' influence on adolescents' adjustment to school. Child Development, 66, 1312 - 1329.

Birch, S. H., \& Ladd, G. W. (1998). Children's interpersonal behaviors and the student-teacher relationship. Developmental Psychology, 34, 934-946.

Bissel-Havran, J.M., \& Loken, E. (2009).The Role of Friends in Early Adolescents' Academic Self-competence and Intrinsic Value for Math and English. Journal of Youth and Adolescence, 38(1), 41-50.

Black, A. E., \& Deci, E. L. (2000). The effects of instructors' autonomy support and students' autonomous motivation on learning organic chemistry: A self-determination theory perspective. Science Education, 84, 740-756.

Blanchard, C. M., Amiot. C., Perreault, S., \& Vallerand, R. J. (2009). Cohesiveness and psychological needs: Their effects on self-determination and athletes' subjective well-being. Psychology of Sport and Exercise, 10, 545-551.

Bloom, B. S. (1977). Affective outcomes of school learning. Phi Delta Kappan, 59, 193-198.

Booth, A., \& Dunn, J. F. (1996). Family - school links: how do they affect educational outcome? Mahwah, NJ: Lawrence Erlbaum Associates.

Bosker R.J. \& Scheerens, J. (1989). Issues in the interpretation of school-effects research. International Journal of Educational Research, 13, 744-751.

Bosworth, K.; Espelage, D., DuBay, T. (1998). A computer-based violence prevention intervention for young adolescents: Pilot study. Adolescence, 33 (132) 785-795.

Bowen, G. L., Richman, J. M., Brewster, A., \& Bowen, N. (1998). Sense of school coherence, perceptions of danger at school, and teacher support among youth at risk of school failure. Child and Adolescent Social Work Journal, 15, 273 - 286.

Boyce, W.T., Frank, E., Jensen, P.S., Kessler, R.C., Nelson, C.A., Steinberg, L., et al., (1998). Social context in developmental psychopathology: Recommendations for future research from the MacArthur Network on Psychopathology and Development. Development and Psychopathology, 10(2), 143-164.

Bradshaw, J., Keung, A., Rees, G. and Goswami, H. (2011). Children's subjective well-being: international comparative perspectives. Children and Youth Services Review, 33, 4, 548556.

Bradshaw, J., \& Richardson, D. (2009): An Index of Child Well-being in Europe. Child Indicators Research, doi:10.1007/s12187-009-9037-7 Available online at http://www.springerlink. com/content/r5kq13v750q53782/?p=76a9631290a7476b9802650b9750b54d\&pi=0\% 20 (accessed on 3 June 2009). 
Bronfenbrenner, U. (1979). The Ecology of Human Development: Experiments by Nature and Design .Cambridge, MA: Harvard University Press.

Bronfenbrenner, U. \& Crouter, A. C. (1983). The evolution of environmental models in developmental research, In W. Kessen (Ed,). Handbook of child psychology. vol. 1, History, theory and methods (pp. 357-414), New York: Wiley.

Brookover, W. B., Beady, C., Flood, P. Schweitzer, J., \& Wisenbaker, J. (1979). School social systems and student achievement. New York: Praeger.

Brophy, J. E. (2004). Motivating students to learn ( $2^{\text {nd }}$ ed.). Mahwah, NJ: Lawrence Erlbaum.

Brown, K. W., \& Kasser, T. (2004). Are psychological and ecological well-being compatible? The role of values, mindfulness, and lifestyle. Social Indicators Research, 74, 349-368.

Burchinal, M. R., Roberts, J. E., Zeisel, S. A., \& Rowley, S. J. (2008). Social risk and protective factors for African American children academic achievement and adjustment during the transition to middle school. Developmental Psychology, 44, 286 - 292.

Byrnes, D. A. (1985). Cipher in the classroom: The invisible child. Childhood Education, 62, 9197.

Cantor, N., \& Harlow, R. (1994). Social intelligence and personality: Flexible life-task pursuit. In R.J. Sternberg \& P. Ruzgis (Eds.), Personality and intelligence (pp. 137-168). Cambridge, U.K.: Cambridge University Press.

Casas, F. (2010a). El bienestar personal: Su investigación en la infancia y la adolescencia. Encuentros en Psicología, 5, (1), 85-101.

Casas, F. (2010b). Indicadores sociales subjetivos y bienestar en la infancia y la adolescencia. En G. González-Bueno, M. von Bredow y C. Brecedóniz, Propuesta de un sistema de indicadores sobre el bienestar infantil en España (pp. 34-51). Madrid: UNICEF-España.

Caulfield, T. J. (1980). The successful ones. Personnel and Guidance Journal, 59, 241-245.

Charlebois, P., Leblanc, M., Gagnon, C., Larivee, S., \& Tremblay, R, (1992). The effect of cumulative subtle coercion in the primary school classroom on juvenile delinquency. Paper presented at the Society for Life History Research Conference in Philadelphia, April 1992.

Cheng, H. \& Furnham, A. (2002). Personality, peer relations, and self-confidence as predictors of happiness and loneliness. Journal of Adolescence, 25, 327-339.

Christenson, S. L. (2004). The Family-School Partnership: An Opportunity to Promote the Learning Competence of All Students. School Psychology Review,33, 1, 83-104.

Christenson, S. L., \& Sheridan, S. M. (2001). Schools and families: Creating essential connections for learning. New York: The Guilford Press.

Chu, P. S., Saucier, D. A., \& Hafner, E. (2010) Meta-analysis of the relationships between social support and well-being in children and adolescents. Journal of Social and Clinical Psychology, 29 (6), 624-645.

Clarke, B. L., Sheridan, S. M. y Woods, K. E. (2010). Elements of healthy family-school relationships. In S. L. Christenson and A. L. Reschly (Eds.), Handbook of School-Family Partnerships. New York, NY: Routledge 
Coleman, J. S, (1961). The adolescent society. New York: Free Press of Glencoe.

Coleman, J. S. (1968). Equality of opportunity. Washington, DC: U.S. Government Printing Office.

Coleman, J. C. (1990). Foundations of Social Theory. Cambridge, Mass.: Harvard University Press.

Coleman, J. S., Campbell, E. Q., Hobson, C. J., McPartland, J., Mood, A. M., Weinfeld, F. D., \& York, R. L. (1966). Equality of educational opportunity. Washington, DC: U.S. Government Printing Office.

Connell, J. P. (2003). Getting off the dime: Toward meaningful reform in secondary schools: Lessons on how model developers and school districts can facilitate the success of school reform. Retrieved January 2008, from http://www.irre.org/publications/pdfs/benchmarks_summer_2003.pdf

Connell, J. P., \& Wellborn, J. G. (1991). Competence, autonomy and relatedness: A motivational analysis of self-system processes. In M. R. Gunnar, \& L. A. Sroufe (Eds.), Self-processes in development: Minnesota Symposium on Child Psychology (Vol. 23, pp. 43 - 77). Hillsdale, $\mathrm{NJ}$ :Erlbaum.

Currie, C., Gabhainn, S.N., Godeau, E., Roberts, C., Smith, R., Currie, D., Picket, W., Richter, M., Morgan, A., \& Barnekow, V. (2008). Inequalities in young people's health: Health Behaviour in school-aged children (HBSC) International Report from the 2005/2006 Survey. Health Policy for Children and Adolescents, No5, Copenhagen: World Health Organization, Regional Office for Europe. http://www.euro.who.int/eprise/main/WHO/InformationSources/Publications/Catalogue/200 80617_1. (accessed 3 June 2009).

Deci E.L.,\& Ryan R.M. (2000). The "what" and "why" of goal pursuits: human needs and the self-determination of behavior. Psychological Inquiry, 11, 227-268

Deci, E. \& Ryan, R. (2011). Levels of analysis, regnant causes of behavior and well-being: The role of psychological needs. Psychological Inquiry, 22, 17-22.

De Fraine, B., Van Landeghem, G., Van Damme, J., \& Onghena, P. (2005). An analysis of wellbeing in secondary school with multilevel growth curve models and multilevel multivariate models. Quality and Quantity, 39, 297-316.

Dekovic, M.; Rutger,C. M.; Engels, E. ; Shirai, T.; de Kort, G. \& Anker, A. L. (2002) The Role of Peer Relations in Adolescent Development in Two Cultures: The Netherlands and Japan . Journal of Cross-Cultural Psychology; 33; 577-595.

DeSanctis King, A.L.; Huebner, E.S.; Suldo, S.M., y Valois, R.F. (2006). An ecological view of school satisfaction in adolescence: Linkages between social support and behavior problems. Applied Research in Quality of Life, 1, 279-295.

Dishion, T. J., Poulin, F., \& Burraston, B. (2001). Peer group dynamics associated with iatrogenic effect in group interventions with high-risk young adolescents. New Directions for Child and Adolescent Development, 2001, $79-82$.

Doo, M.Y. (2006). A problem in online interpersonal skills training: Do learners practice skills? Open Learning: The Journal of Open and Distance Learning, 21 (3), 263-272. 
Droege, K. L., \& Howes, C. (1991). The influence of caregiver sensitivity on children's affective displays. Poster presented to the International Society for the Study of Behavioral Development, Minneapolis, MN, July, 1991.

Eccles, J. S., Barber, B.L. ,Stone, M. , \& Hunt J. (2003). Extracurricular Activities and Adolescent Development. Journal of Social Issues, 59(4), 865-889.

Eccles, J.S., Brown, B.V., \& Templeton, J. (2008). A developmental framework for selecting indicators of well-being during the adolescent and young adult years. In B.V. Borwn (Ed.), Key indicators of child and youth well-being (pp. 197-236). New York, NY: Lawrence Erlbaum Associates.

Eccles, J. S., Lord, S., \& Midgley, C. M. (1991). What are we doing to adolescents? The impact of educational contexts on early adolescents. American Journal of Education, 99, 521 - 542.

Eccles, J. S., \& Midgley, C. (1989). Stage/environment fit: Developmentally appropriate classrooms for early adolescents. In R. Ames \& C. Ames (Eds.), Research on motivation in education (Vol 3, pp. 139-181). New York: Academic Press.

Eccles, J. S., \& Roeser, T. (1999). School and community influences on human development. In M. Bornstein \& M. Lamb (Eds.), Developmental psychology: An advanced textbook (4th ed., pp. 503-554). Mahwah, NJ: Lawrence Erlbaum.

Eccles, J. S., \& Roeser, R. W. (2003). Schools as developmental contexts. In G. Adams (Ed.), Handbook of Adolescence (pp. 129 - 148). Oxford, UK: Blackwell Press.

Eccles, J.S. \& Roeser, R.W. (2009). Schools, Academic Motivation, and Stage-Environment Fit. In R.M. Lerner and L. Steinber (Eds.), Handbook of adolescent psychology (3rd ed.)(pp. 404 - 434). Hoboken, N.J.: John Wiley \& Sons.

Eccles, J.S. \& Roeser, R.W. (2011). Schools as developmental context during adolescence. Journal of Research on Adolescence, 21(1), 225 - 241.

Eccles, J. S., \& Templeton, J. (2002). Extracurricular and other after-school activities for youth. Review of Research in Education, 26, 113 - 180.

Edmonds, R. (1986). Characteristics of effective schools. In U. Neisser [Ed.), The school achievement of minority children (pp. 93-104). Hillsdale, NJ: Erlbaum.

Epstein, J. L. (1983). Longitudinal effects of family-school-person interactions on student outcomes. In A. C. Kerckhoff (Ed.), Research in sociology of education and socialization (pp. 101-127). Greenwich, Conn.: JAI Press.

Epstein, J. (1997). School, family and community partnership. Thousand Oaks, California: Corwin Press, INC.

Epstein, J. L., \& Karweit, N. (Eds.) (1983). Friends in school: Patterns of selection and influence in secondary schools. New York: Academic Press.

Erikson, E.H. (1963). Childhood and society. (2nd ed.).New York: Norton. (Original work published 1950).

Erikson, E.H. (1968). Identity: Youth and crisis. New York: Norton.

Erwin, P. G. (1994). Effectiveness of social skills training with children: A meta-analytic study. Counselling Psychology Quarterly, 7(3), 305-310. 
Farkas, M. S. \& Grolnick, W. S. (2010). Examining the components and concomitants of parental structure in the academic domain. Motivation and Emotion; 34, 266-279.

Feshhach, N. D. (1967). Effects of teachers' reinforcement style upon children's imitation and preferences. Proceedings of the 75th annual convention of the American Psychological Association, 2, 281-282.

Finn, J. D. (1989). Withdrawing from school. Review of Educational Research, 59, 117-142.

Finn, J. D. (2006). The adult lives of at-risk students. Report to National Center of Educational Statistics, Washington, DC: U. S. Department of Education NCES 2006 - 328.

Finn, J. D., Gerber, S. B., Achilles, C. M., \& Boyd-Zacharias, J. (2001). The enduring effects of small classes. Teachers College Record, 103(2), 145 - 183.

Fiqueira-McDonough, J. (1986). School context, gender, and delinquency. Journal of Youth and Adolescence, 15, $79-98$.

Flaspohler, P.D., Elfstrom, J.L., Vanderzee, K.L., Sink, H.E., \& Birchmeier, Z. (2009). Stand by me: The effects of peer and teacher support in mitigating the impact of bullying on quality of life. Psychology in the Schools, 46(7), 636-649.

Flanders, N., \& Havumaki, S. (1960). The effect of teacher-pupil contacts involving praise on sociometric choices of students. Journal of Educational Psychology, 51, 65-68.

Flourio-Ruane, S. (1989). Social organization of classes and schools. In M. Reynolds (Ed.), Knowledge base for the beginning teacher. A handbook (pp. 163-172). Oxford, U.K.: Pergamon Press.

Forest, C., \& García, F.J. (2006). Comunicación cooperativa entre la familia y la escuela. Valencia: Nau llibres

Fortier, M. S.,Vallerand, R. J., \& Guay, F. (1995). Academic motivation and school performance: Toward a structural model. Contemporary Educational Psychology, 20, 257274

Frank, K. A., Schiller, K. S., Riegle-Crumb, C., Mueller, A. S., Crosnoe, R., Pearson, J., et al. (2008). The social dynamics of mathematics course taking in high school. American Journal of Sociology, 113, 1645 - 1696.

French, D. C., Pidada, S.,\& Victor, A. (2005). Friendships of Indonesian and United States youth. International Journal of Behavioral Development, 29(4), 304-313.

Frones, I. (2007). Theorizing indicators. Social Indicators Research, 83(1), 5-23.

Furman, W., \& Robbins, P. (1985). What's the point? Issues in the selection of treatment objectives. In B. H. Schneider, K. H. Rubin, \& J. E. Ledingham (Eds.), Children's peer relations: Issues in assessment and intervention (pp. 41--54). New York: Springer-Verlag.

Furrer, C., \& Skinner, E. A. (2003). Sense of relatedness as a factor in children's academic engagement and performance. Journal of Educational Psychology, 95, 148-162.

Gambone, M.A., Klem, A. M., \& Connell, J. P. (2002). Finding out what matters for youth: Testing key links in a community action framework for youth development. Philadelphia: Youth Developmemt Strategies. 
García-Bacete, F. J. (1998). Aproximación Conceptual a las Relaciones Escuela-Familia. Bordón 50 (1), 23-34.

Garcia Bacete, F. J. (2003). Las relaciones escuela-familia: un reto educativo. Infancia y aprendizaje, 26 (4), 425-437.

García-Bacete, F. J. (2006). Cómo son y cómo podrían ser las relaciones entre escuelas y familias en opinión del profesorado. Cultura y Educación, 18 (3-4), 247-265.

García-Bacete, F. J. (2009). Formación inicial del profesorado y de los psicopedagogos en educación de la convivencia (monográfico). Revista Educar, 43, 43-60

García-Bacete, F. J., \& Martínez-González, R. A. (2006). La relación entre los centros escolares, las familias y los entornos comunitarios como factor de calidad de la educación de menores y adultos. Cultura y Educación 18 (3-4), 213-218.

García-Bacete, F. J.,\& Traver, J. (2010). Familias, centros educativos y comunidad. En F. J. García-Bacete, A. V. Vaquer y C. Gomis (Coords.), Intervención y Mediación Familiar (pp. 205-250). Castellón: Publicacions de la Universitat Jaume I. Colección Universitas.

Garcia-Reid, P., Reid, R. J., \& Peterson, N. A. (2005). School engagement among Latino youth in an urban middle school context: Valuing the role of social support. Education and Urban Society, 37(3), $257-275$.

Gershoff, E.T., \& Aber, J. L. (2006). Neighborhoods and schools. Contexts and consequences for the Mental health and risk behaviors of children and youth. In L. Balter, \& C.S. Tamis-Le Monda, Child psychology: A handbook of contemporary issues (2nd Ed.) (pp.611 - 645). New York, NY: Psychological.

Getzels, J. W. (1975). Images of the classroom and visions of the learner. In T. G. David, \& B. D. Wright (Eds.), Learning environments (pp. 1-14). Chicago: University of Chicago Press.

Giaconia, R. M., \& Hedges, L. V. (1982). Identifying features of effective open education. Review of Educational Research, 52, 579-602.

Gifford-Smith, M. E. \& Brownell, C. A. (2003). Childhood peer relationships: Social acceptance, friendships and peer networks. Journal of School Psychology, 41, 235 - 284

Gilman, R., \& Huebner, E.S. (2000). Review of life satisfaction measures for adolescents. Behaviour Change, 17, 178-196.

Gilman, R., Meyers, J., \& Perez, L. (2004). Structured extracurricular activities among adolescents: Findings and implications for school psychologists. Psychology in the Schools, $41,31-41$.

Gladwell, M. (2000). The tipping point: How little things can make a big difference. New York: Little, Brown.

Goldstein, A. P., \& Glick, B. (1987). Aggression replacement training. Champaign, IL: Research Press.

Goldstein, H., Yang, M., Omar, R., Turner, R., \& Thompson, S. (2000). Meta-analysis using multilevel models with an application to the study of class size effects. Journal of the Royal Statistical Society. Series C, 49, 399-412. 
Good, T. L., \& Brophy, J. F. (1986). School effects. In M. C. Wittrock (Ed.), Handbook of research on teaching (pp. 570--602). New York: Macmillan.

Goodland, S., \& Hirst, B. (1989). Peer tutoring. London: Kogan-Page.

Grabe, M. (1981). School size and the importance of school activities. Adolescence, 16, 21-31.

Graham, S., \& Taylor, A. Z. (2002). Ethnicity, gender, and the development of achievement values. In A. Wigfield \& J. S. Eccles (Eds.), Development of achievement motivation (pp. 123 - 146). San Diego: Academic Press.

Greenwald, R., Hedges, L. V., \& Laine, R. D. (1996). The effect of school resources on student achievement. Review of Educational Research, 66, 361-396.

Gregory, A., Dewey, D., Fan, X., Sheras, P., Shih, T.-H., \& Huang, F. (2010). Authoritative school discipline. Journal of Educational Psychology, 102, 483 - 496.

Grolnick, W. S., Gurland, S. T., Jacob, K. F., \& Decourcey, W. (2002). The development of selfdetermination in middle childhood and adolescence. In A. Wigfield \& J. S. Eccles (Eds.), Development of achievement motivation (pp. 147-171). San Diego: Academic Press.

Grolnick, W. S., \& Pomerantz, E. M. (2009). Issues and challenges in studying parental control: Toward a new conceptualization. Child Development Perspectives, 3, 165-170.

Grolnick, W. S., Ryan, R. M., \& Deci, E. L. (1991). The inner resources for school performance: Motivational mediators of children's perceptions of their parents. Journal of Educational Psychology, 53, 508-517.

Guay, F., Mageau, G. A., \& Vallerand, R. J. (2003). On the hierarchical structure of selfdetermined motivation: A test of top-down, bottom-up, reciprocal, and horizontal effects. Personality and Social Psychology Bulletin, 29, 992-1004.

Guay, F., \& Vallerand, R. J. (1997). Social context, student's motivation, and academic achievement: Toward a process model. Social Psychology of Education, 1, 211-233.

Hansell, S., \& Karweit. N. (1983). Curricular placement, friendship networks, and status attainment. In J. L. Epstein, \& N. Karweit (Eds.), Friends in school (pp. 141-161). New York: Academic Press

Hansen, D. A. (1986). Family -school articulations: The effects of interaction rule mismatch. American Educational Research Journal, 23, 643-659.

Hartup, W. W., \& Stevens, N. (1997). Friendships and adaptation in the life course. Psychological Bulletin, 121, 355-370.

Hattie, J. (2009). Visible learning. New York, NY: Routledge.

Hawkins, J., \& Berndt. T. J. (1985), Adjustment following the transition to Junior High School. Paper presented at the biennial meeting of the Society for Research in Child Development, Toronto, Canada.

Hawkins, J. D., Kosterman, R., Catalano, R. F, Kill, K. G., \& Abbott, R. D. (2008). Effects of Social Development Intervention in childhood 15 years later. Archives of Pediatrics and Adolescent Medicine, 162, 1133-1141. 
Hedges, L. V., Laine, R. D., \& Greenwald, R. (1994). Money does matter somewhere: A reply to Hanushek. Educational Researcher, 9-10 (May).

Henderson, A., \& Mapp, K.C. (2002). A New Wave of Evidence: The Impact of School, Family, and Community Connections on Student Achievement. Austin, National Center for Family and Community Connections with Schools. Southwest Educational Development Laboratory.

Henderson-King, D., \& Mitchell, A, M. (2011). Do materialism, intrinsic aspirations, and meaning in life predict students' meaning of education? Social Psychological Education, 14, 119-134.

Heyneman, S., \& Loxley, W. (1983). The effect of primary school quality on academic achievement across twenty-nine high and low income countries. American Journal of Sociology, 88(6), 1162-1194.

Hill, P. W., \& Rowe, K. J. (1996). Multilevel modeling in school effectiveness research. School Effectiveness and School Improvement, 7, 1-34.

Hinde, R. A., Stevenson-Hinde, J., \& Tamplin, A. (1985). Characteristics of 3-to 4-year-olds assessed at home and their interactions in preschool. Developmental Psychology, 21, 130140.

Hodges, E. V. E., Boivin, M., Vitaro, F., \& Bukowski,W. M. (1999). The power of friendship: Protection against an escalating cycle of peer victimization. Developmental Psychology, 35, 94-101.

Hoffman, M. A., Ushpiz, V., \& Levy-Shiff, R. (1988). Social support and self-esteem in adolescence. Journal of Youth and Adolescence, 17, 307-316.

Homel, R.; Burns, A.; Goodnow, J. (1987). Parental Social Networks and Child Development. Journal of Social and Personal Relationships.4(2), 159-177.

Hoover-Dempsey, K. V.; Walker, J. M. T., Sandler, H. M., Whetsel, D., Green, C. L., Wilkins, A. S.\& Closson, K.E. (2005). Why do parents become involved? Research findings and implications. Elementary School Journal, 106 (2), 105-130.

Hopkins, D., \& Reynolds, D. (2001). The past, present and future of school improvement:Towards the third age. British Educational Research Journal, 27, 459-475.

Howlin, P. (2002). Special educational treatment. In M. Rutter, \& E. Taylor (Eds.), Child and adolescent psychiatry (4th ed.) ( pp. 1128-1147). Oxford, UK: Blackwell.

Huebner, E.S. (2004). Research on assessment of life satisfaction of children and adolescents. Social Indicators Research, 66, 1-2, 3-33.

Huebner, E.S., y Gilman, R. (2006). Students who like and dislike school. Applied Research in Quality of Life, 1, 139-150.

Isherwood, G. I., \& Ahola, J. A. (1981). School life: A conceptual model, or where you stand depends on where you sit. In J. K. Epstein (Ed .), The quality of school life (pp. 173-177). Lexington, MA: Lexington Books.

Ittelson, W. H., Rivlin, L. G., \& Proshansky, M. (1970). The use of behavioral maps in environmental psychology. In M. Proshansky, W. H. Ittelson, \& L. G. Rivkin (Eds.), 
Environmental psychology: man and his physical setting (pp. 658-668). New York: Holt, Rinehart \& Winston.

Johnson, D. W., Maruyama, R., Johnson, R., Nelson, D., \& Skon, L. (1981). Effects of cooperative, competitive and individualistic goal structures on achievement: A metaanalysis. Psychological Bulletin, 89, 47-62.

Johnson, D. W., \& Johnson, R. T. (1975). Learning together and alone: Cooperation, competition and individualization. Englewood Cliffs, NJ: Prentice-Hall.

Johnson, M. W. (1935). The effect on behavior of variation in the amount of play equipment. Child Development, 6, 56-68.

Jowett, S., Baginsky, M., \& MacDonald, M. (1991). Building bridges: parental involvement in schools. Windsor, UK: NFER/Nelson.

Kagan, D. M. (1990). How schools alienate students at risk: A model for examining proximal classroom variables. Educational Psychologist, 25(2), 105-125.

Kagan, S. (1999). Cooperative Learning. San Clemente: Resources for Teachers, Inc

Kagan, S., \& Kagan M. (2009). Kagan Cooperative Learning. San Clemente, CA: Kagan Publishing.

Kaplan, A., \& Maehr, M. L. (1999). Achievement goals and student well-being. Contemporary Educational Psychology, 24(4), 330-358.

Kasen, S.N., Johnson, P.N., \& Cohen, P.N. (1990). The impact of social emotional climate on student psychopathology. Journal of Abnormal Child Psychology, 18 (2), 165-177.

Kasser, T. (2002). Sketches for a self-determination theory of values. In E. L. Deci \& R. M. Ryan (Eds.), Handbook of Self-Determination Research (pp. 123-140). Rochester, NY: University Of Rochester Press.

Kasser, T., \& Ahuvia, A. C. (2002). Materialistic values and well-being in business students. European Journal of Social Psychology, 32, 137-146.

Kasser, T., \& Ryan, R. M. (1993). A dark side of the american dream: Correlates of financial success as a central life aspiration. Journal of Personality and Social Psychology, 65, 410422.

Kasser, T., \& Ryan, R. M. (1996). Further examining the american dream: Differential correlates of intrinsic and extrinsic goals. Personality and Social Psychology Bulletin, 22, 280-287.

Kernis, M. H. (2003). Optimal self-esteem and authenticity: Separating fantasy from reality. Psychological Inquiry, 24, 83-89.

Kernis, M. H., \& Goldman, B. M. (2006). A multicomponent conceptualization of authenticity: Theory and research. In M. P. Zanna (Ed.), Advances in experimental social psychology (pp. 284-357). San Diego: Elsevier Academic Press.

Kerns, K.A. (1996). Individual differences in friendship quality and their links to child-mother attachment. In W.M. Bukowski, A.F. Newcomb, \& W.W. Hartup (Eds.), The company they keep: Friendship in childhood and adolescence (pp. 137-157). Cambridge University Press. 
Kiuru, N., Aunola K., Vuori, J., \& Nurmi, J.-E. (2007). The role of peer groups in adolescents' educational expectations and adjustment. Journal of Youth and Adolescence, 36, 995-1009.

Klindova, L. (1985). Longitudinalne sledovanie niektorych ukazovatel'ov socialnej aktivity y predskolson veku [Longitudinal investigation of some indicators of social activity in preschoolers]. Psychológia a Patopsychológia Dietata, 20,483 496.

Knee, R. \& Uysal, G. (2011). The role of autonomy in promoting healthy dyadic, familial and parenting relationships across cultures. In Chirkov, V., Ryan, R., Sheldon, K. (Eds.), Human autonomy in cross-cultural context: Perspectives on the psychology of agency, freedom, and well-being. (pp. 95-110), New York, NY, US: Springer Science and Business Media.

Kohlberg, L. (1970). Education for justice: A modern statement of the Platonic view. In N. F. Sizer \& T. R. Sizer (Eds.), Moral education: Five lectures. Cambridge, MA: Harverd University Press.

Kyriakides, L., Creemers , B., Antoniou, P/ \& Demetriou, D. (2010). A synthesis of studies searching for school factors: implications for theory and research. British Educational Research Journal, 5, 807-830.

Ladd, G. W., Kochenderfer, B. J., \& Coleman, C. C. (1996). Friendship quality as a predictor of young children's early school adjustment. Child Development, 67, 1103-1108.

LaFreniere, P. J. \& Sroufe, L. A. (1985). Profiles of peer competence in the preschool: Interrelations between measures, influence of social ecology, and relation to attachment history. Developmental Psychology, 21, 56-69.

Lagacé-Séguin, D. G. \& Case, E. (2010). Extracurricular activity and parental involvement predict positive outcomes in elementary schools. Early Child Development and Care, 180 (4), 453-462.

Lando, B. Z., \& Schneider, B. H. (1997). Intellectual contributions and mutual support among developmentally advanced children in homogeneous and heterogeneous work/discussion groups. Gifted Child Quarterly, 41, 44-57.

Lane R.E. (2000).The loss of happiness in market democracies. New Haven CT: Yale

Larson, R. W. (2000). Toward a psychology of positive youth development. American Psychologist, 55, $170-183$.

LeBlanc, L., Swisher, R., Vitaro, F., \& Tremblay, R. E. (2007). School social climate and teachers' perceptions of classroom behavior problems: A ten-year longitudinal and multilevel study. Social Psychology in Education, 10, 429 - 442.

Legendre, A. (1987). Transformation de l'espace d'activités et échanges sociaux de jeunes enfants en crèche. Psychologie Française, 32, 31-43.

Legendre, A. (1989). Young children's social competence and their use of space in day-care centers. In B. H. Schneider, G. Attili, J. Nadel \& R. P. Weissberg (Eds,), Social competence in developmental perspective (pp. 263-276). Dordrecht: Kluwer Academic Publishers.

Leithwood, K., \& Jantzi, D. (2009). A review of empirical evidence about school size effects. Review of Educational Research, 79, $464-490$. 
Levin, H. M. (1998). Accelerated schools for at-risk students. CPRE Research Report Series RR010. Center for Policy Research in Education, Eagleton Institute of Politics, Rutgers, The State University of New Jersey, New Brunswick.

Lewin, K. (1954). Behavior and development as a function of the total situation. In L. Carmichael (Ed.). Manual of child psychology (pp. 918-970). New York: Wiley.

Lewin, K., Lippitt, R., \& White, R. (1939). Patterns ofaggressive behavior in experimentally created social climates. Journal of Social Psychology. 10,271-299.

Light, R.J., \& Pillemer, D.B. (1984). Summing up: The science of reviewing research. Cambridge, MA: Harvard University Press.

Linnenbrink-Garcia, L. \& Fredricks, J. A. (2008). Developmental perspectives on achievement motivation: Personal and contextual Influences. In J. Y. Shah and W. L. Gardner (Eds.), Handbook of Motivation Science, (pp. 448-464), New York, NY, US: The Guilford Press.

Lipsitz, J. (1984). Successful schools for young adolescents. New Brunswick, NJ: Transaction Books.

Loranger, M. (1984). Social skills ill the secondary school. Paper presented at the Conference on Research Strategies in Children's Social Skills Training, Ottawa, Ontario, June 1984.

Lucas, S. R. (1999). Tracking inequality: Stratification and mobility in American high schools. New York: Teachers College Press.

Luyten, H. \& Sammons, P. (2010). Multilevel modeling. In B.P.M. Creemers, L. Kyriakides \& P. Sammons (Eds.), Methodological advances in educational effectiveness research (pp. 246-276). Abingdon, UK: Routledge.

Madsen, M. C., \& Shapira, A. (1970). Cooperative behavior of urban Afro-American. AngloAmerican and Mexican village children. Developmental Psychology, 3, 16-20.

Maehr, M. L., \& Midgley, C. (1996). Transforming school cultures to enhance student motivation and learning. Boulder, $\mathrm{CO}$ : Westview.

Mahoney, J.L., \& Cairns, R.B. (1997). Do extracurricular activities protect against early school dropout? Developmental Psychology, 33, 241-253.

Manetti, M., \& Campart, M. (1987). Spazio e interazione in gruppo pre-scolare: Struttura della communicazione [Space and interaction in the preschool group: Communication structure]. In L. Camaioni (Ed.), Origille e sviluppo della competenza sociale infantile (pp. 155-180). Milan: Angeli.

Manetti, M., \& Campart, M. (1989). The structure of communication: space and interaction in a pre-school group. In B. H. Schneider, G. Attili, J. Nadel, \& R. Weissberg (Eds). Social Competence in Developmental Perspective (pp. 405---406). Dordrecht, Netherlands: Kluwer.

Marjoribanks, K. (2004). Immigrant adolescents' individual and environmental influences on young adults' educational attainment. Journal of Comparative Family Studies, 35, 485-499

Marsh, H. W., Trautwein, U., Lüdtke, O., \& Brettschneider, W. (2008). Social comparison and big-fish-little-pond effects on self-concept and other self-belief constructs. Role of generalized and specific others. Journal of Educational Psychology, 100, 510 - 524. 
Mayer, D. P., Mullens, J. E., \& Moore, M. T. (2000).Monitoring school quality: An indicators report (NCES 2001-030). Washington, DC: U.S. Departament of Education.

McDill, E. L., \& Rigsby, L. C. (1973). Structure and process in secondary schools: The academic impact of educational climates. Baltimore, MD: Johns Hopkins University Press.

McGrath, H., \& Noble, T. (2010). Supporting positive pupil relationships : research to practice. Educational \& child psychology, 27 (1), 79-90.

Medinnus, G. (1962). An examination of several correlates of sociometric status in a first-grade group. Journal of Genetic Psychology, 101, 3-13.

Meece, J. L., Anderman, E. M., \& Anderman, L. H. (2005). Classroom goal structure, student motivation and academic achievement. Annual Review of Psychology, 57, 487 - 503.

Melton, G.B., Limber, S.P., \& Teague, T. L. (2000). Changing schools for changing families. In R.C. Pianta \& M. J. Cox (Eds.), The transition to kindergarten (pp. 179-213). Baltimore, MD: Paul. H. Brookes Publishing Co.

Monjas, M. I., Sureda, I., \& García-Bacete, F. J. (2008). ¿Por qué los niños y las niñas se aceptan y se rechazan? Cultura y Educación, 20 (4), 479-492.

Moos, R. (1979). Evaluating educational environments: Methods, procedures, findings, and policy implications. San Francisco: Jossey Bass.

Moreno, J. L. (1953). "Who shall survive? Foundations of sociometry, group psychotherapy and sociodrama”. New York: Beacon House.

Mortimore, P. (1998). The road to improvement: Reflections on school effectiveness. Lisse, Netherlands: Swets \& Zeitlinger.

Navarrate, L.A. (1999). Melancholy in the millennium: A study of depression among adolescents with and without learning disabilities. High School Journal, 82(3), 137-149.

National Center for Education Statistics. (2000). Condition of America's public school facilities: 1999 (NCES 2000-032). Washington, DC: U.S. Departament of Education.

Neill, R. S. SI. J. (1982). Experimental alterations in playroom layout and their effect on staff and child behavior. Educational Psychology, 2, 103-119.

Newcomb, A. F., \& Bagwell, C. L. (1996). The developmental significance of children's friendship relations. In W. M. Bukowski, A. F. Newcomb, \& W. W. Hartup (Eds.), The company they keep: Friendship in childhood and adolescence (pp. 289-321). New York: Cambridge University Press.

Noddings, N. (2003). Happiness in education. Cambridge, U.K: Cambridge

Ntoumanis, N. (2005). A prospective study of participation in optional school physical education based on self-determination theory. Journal of Educational Psychology, 97, 444-453.

Oakes, J. (2005). Keeping track (2nd ed.). New Haven, CT: Yale University Press.

Oberle , E. Schonert-Reichl, K.S., \& Zumbo, B.D. (2011). Life Satisfaction in Early Adolescence: Personal, Neighborhood, School, Family, and Peer Influences. Journal of Youth and Adolescence, 40, 889-901 
Ochaita, E., Augustin, S., \& Espinosa, M.A. (2010). Indicadores de bienestar infantil: la teoría de derechos y necesidades de la infancia como marco teórico y organizativo. In $\mathrm{G}$.

González-Bueno, M. von Bredow y C. Brecedóniz, Propuesta de un sistema de indicadores sobre el bienestar infantil en España (pp. 52-66). Madrid: UNICEF-España.

Olweus, D. (1991 ). Bully/victim problems among schoolchildren: Basic facts and effects of a school based intervention program. In K. Rubin \& D. Pepler (Eds.), The development and treatment of childhood aggression (pp. 411-448). Hillsdale, NJ: Erlbaum.

Pellegrini, A. D., \& Perlmutter, J. C. (1989). Classroom contextual effects on children's play. Developmental Psychology, 25, 289-296.

Peres, Y., \& Pasternack, R. (1991). To what extent can the school reduce the gaps between children raised by divorced and intact families? Journal of Divorce and Remarriage, 15(3/4): 143-158.

Perry, H. S. (1982). Psychiatrist of America: the life of Harry Stack Sullivan. Harvard: Belknap

Phillips, E. L. (1978). The social skills basis of psychopathology. New York: Grune \& Stratton.

Pianta, R. C., (2006). Schools, Schooling, and Developmental Psychopathology. In D. Cicchetti \& D. J. Cohen (2006 Eds.), Developmental psychopathology, Vol I: Theory and Method (2nd Ed.) (pp. 494 - 529). Hoboken, NY: John Wiley \& Sons.

Pigott, H, E., Fantuzzo, J, W., \& Clement, P. W. (1986). The effect of reciprocal tutoring and group contingencies on the academic performance and peer rankings of elementary school students in three regular classrooms. Journal of Applied Behavior Analysis. 19, 93-98.

Pollard, E.L. \& Lee, P. D. (2003). Child well-being: A systematic review of the literature. Social Indicators Research, 61, 59-78.

Portugues, S. H., \& Feshbach, N. D. (1972). The influence ofsex and socioethnicfactors upon imitation of teachers by elementary school children. Child Development, 43, 981-989.

Powell, D.R., Peet, S.H., \& Peet, C.E. (2002). Low-income children's academic achievement and participation in out-of-school activities in first grade. Journal of Research in Childhood Education, 16, 202-211.

Prohansky, H. M. (1974), Theoretical issues in environmental psychology, In T, G. David \& B, D. Wright (Eds,), Learning environments (pp, 91-94). Chicago: University of Chicago Press.

Purkey, S., \& Smith, M. (1983). Effective schools: a review. The Elementary School Journal, 83(4), 427-452.

Putallaz, M.,\& Gottman, J. M. (1981), Social skills and group acceptance. In S, R. Asher \& J. M. Gottman (Eds,), The development of children's friendships (pp, 116-149), Cambridge, U.K.: Cambridge University Press.

Putnam, R. D. (1995). Bowling Alone: America's Declining Social Capital. The Journal of Democracy, 6 (1), 65-78.

Pyhalto, Kirsi, Soini, Tiina \& Pietarinen. (2010). Pupils' pedagogical well-being in comprehensive school--Significant positive and negative school experiences of Finnish ninth graders. European Journal of Psychology of Education, 25, 207-221. 
Ramstetter, C L., Murray, R., \& Garner, A. S. (2010). The crucial role of recess in schools. Journal of School Health, 80(11), 517-526.

Ready, D. D., \& Lee, V. E. (2008). Choice, equity, and schools-within-schools reform. Teachers College Record, 110, 1930 - 1958.

Reeve, J. (2006). Teachers as facilitators: What autonomy-supportive teachers do and why their students benefit. Elementary School Journal, 106, 225-236.

Reeve, J. (2009). Why teachers adopt a controlling motivation style toward students and how they can become more autonomy supportive. Educational Psychologist, 44, 159-175.

Reeve, J. \& Assor, A. (2011). Do social institutions necessarily suppress individuals' need for autonomy? The possibility of schools as autonomy-promoting contexts across the globe. In Chirkov, V., Ryan, R., Sheldon, K. (Eds.), Human autonomy in cross-cultural context: Perspectives on the psychology of agency, freedom, and well-being, (pp. 111-132). New York, NY, US: Springer Science and Business Media.

Reeve, J., \& Deci, E. L. (1996). Elements within the competitive situation that affect intrinsic motivation. Personality and Social Psychology Bulletin, 22, 24-33.

Reeve, J., \& Halusic, M. (2009). How k-12 teachers can put self-determination theory principles into practice. Theory and Research in Education, 7, 145-154.

Reeve, J., \& Jang, H. (2006). What teachers say and do to support students' autonomy during a learning activity. Journal of Educational Psychology, 98, 209-218.

Reeve, J., Jang, H., Hardre, P., \& Omura, M. (2002). Providing a rationale in an autonomysupportive way as a strategy to motivate others during an uninteresting activity. Motivation and Emotion, 26, 183-207.

Resnick, M. D., Bearman, P. S., Blum, R. W., Bauman, K. E., Harris, K. M., Jones, J., et al. (1997). Protecting adolescents from harm: Findings from the National Longitudinal Study on Adolescent Health. Journal of American Medical Association, 278, 823-832

Richard, J., Schneider, B. H., \& Mallet, P. (in press). Revisiting the whole-school approach to bullying: Really looking at the whole school. School Psychology International.

Roeser, R.W. (1998). On schooling and mental health: Introduction to the special issue. Educational Psychologist, 33, 129-133

Roeser, R. W., Eccles, J. S., \& Sameroff, A. J. (1998a). Academic and emotional functioning in early adolescence: Longitudinal relations, patterns, and prediction by experience in middle school. Development and Psychology, 10, $321-352$.

Roeser, R.W., Eccles, J.S. \& Strobel, K. (1998b). Linking the study of schooling and mental health: Selected issues and empirical illustrations at the level of the individual. Educational Psychologist, 33, 153-176.

Roeser,R.W., Marachi, R., \& Gelhbach, H. (2002). A goal theory perspective on teachers' professional identities and the contexts of teaching. In C.M. Midgley (ED.), Goals, goal structures, and patterns of adaptative learning (pp.205-241). Mahwah, NJ: Lawrence Erlbaum. 
Roeser, R. W., Peck, S. C. \& Nasir, N. S. (2006). Self and identity processes in school motivation, learning, and achievement. In P. A. Alexander \& P. H. Winne (Eds.), Handbook of educational psychology, (2nd ed.) (pp. 391 - 424). Mahwah, NJ: Erlbaum.

Roeser, R. W., Urban, T, \& Stephens, J. C. (2009). School as a context of motivation and development. In K.Wentzel \& A.Wigfield (Eds.), Handbook of motivation at school (pp. 381-410). Mahwah, NJ: Lawrence Erlbaum.

Rogers, C. (1959). A Theory of Therapy, Personality and Interpersonal Relationships as Developed in the Client-centered Framework. In (ed.) S. Koch, Psychology: A Study of a Science. Vol. 3: Formulations of the Person and the Social Context. New York: McGraw Hill.

Roseth, C. J., Johnson, D. W., \& Johnson, R. T. (2008). Promoting early adolescents' achievement and peer relationships: The effects of cooperative, competitive and individualistic goal structures. Psychological Bulletin, 134, 223 - 246.

Roth, G., Assor, A., Niemiec, C. P., Ryan, R. M., \& Deci, E. L. (2009). The emotional and academic consequences of parental conditional regard: Comparing conditional positive regard, conditional negative regard, and autonomy support as parenting practices.

Developmental Psychology, 45, 1119-1142.

Ruini, C.; Ottolini, F.; Tomba, E.; Belaise, C.; Albieri, E.; Visani, D.; Offidani, E.; Caffo, E.; Fava, G. A. (2009). School intervention for promoting psychological well-being in adolescence. Journal of Behavior Therapy and Experimental Psychiatry. 40(4), 522-532.

Rumberger, R. W., \& Palardy, G. J. (2005). Does segregation still matter? Teacher College Record, 107, $1999-2045$.

Rutter, M.,\& Maughan, B. (2002) School Effectiveness Findings 1979-2002. Journal of School Psychology, 40, (6), $451-475$.

Rutter, M., Maughan, B., Mortimore, P., Ouston, J., \& Smith, A. (1979). Fifteen thousand hours. Cambridge: Harvard University Press.

Ryan, A. M. (2000). Peer groups as a context for the socialization of adolescents' motivation,engagement, and achievement in school. Educational Psychologist, 35, 101-111.

Ryan, A. M. (2001). The peer group as a context for the development of young adolescent motivation and achievement. Child Development, 72, 1135-1150.

Ryan, R. M., \& Brown, K. W. (2005). Legislating competence: The motivational impact of high stakes testing as an educational reform. In A. E. Elliot \& C. Dweck (Eds.), Handbook of competence (pp. 354-374). New York: Guilford Press.

Ryan, R. M., \& Deci, E. L. (2000). Self-determination theory and the facilitation of intrinsic motivation, social development, and well-being. American Psychologist, 55, 68-78.

Ryan, R. M., \& Deci, E. L. (2002). An overview of self-determination theory: An organismicdialectical perspective. In E. L. Deci \& R. M. Ryan (Eds.), Handbook of self-determination research (pp. 3-33). Rochester, NY: University of Rochester Press.

Ryan, R. M., \& Deci, E. L. (2009). Promoting self-determined school engagement, motivation, learning and well-being. In K. R. Wenzel, \& A. Wigfield, (Eds). (2009). Handbook of 
Motivation at School, (pp. 171-196). New York, NY, US: Routledge/Taylor \& Francis Group; US.

Ryan, R. M., Stiller, J., \& Lynch, J. H. (1994). Representations of relationships to teachers, parents, and friends as predictors of academic motivation and self-esteem. Journal of Early Adolescence, 14, 226-249.

Samdal, O., Wold, B. \& Bronis, M., (1999). Relationship between students' perceptions of school environment, their satisfaction with school and perceived academic achievement: An international study. School Effectiveness and School Improvement, 10, 296-320.

Sarason, S. B. (1990). The predictable failure of educational reform: Can we change course before it's too late? San Francisco: Jossey-Bass.

Schaps, E. (2003). The heart of a caring school. Educational Leadership, 60, 31 - 33.

Scheerens, J. \& Bosker, R. (1997). The foundations of educational effectiveness. Oxford: Pergamon.

Schneider, B. (1992). Didactic methods for enhancing children's peer relations: A quantitative review. Clinical Psychology Review, 12, 363-382.

Schneider, B, H., \& Byrne, B. (1987), Individualizing social skills training for behaviordisordered children. Journal of Consulting and Clinical Psychology, 55, 444-445.

Schneider, B. H. , Lee, M.D., \& Alvarez-Valdivia, I. (2011). Adolescent friendship bonds in cultures of connectedness. In Laursen, B., \& Collins, W. A. (Eds.). Relationship pathways: From adolescence to young adulthood. Thousand Oaks, CA: Sage.

Schneider, B. H., Tomada, G., Normand, S., Tonci, E., \& deDomini, P. (2008). Social support as a predictor of school bonding and academic motivation following the transition to Italian middle school. Journal of Social and Personal Relationships, 25, 287-310.

Seilström,E., \& Bremberg, S. (2006). Is there a "school effect" on pupil outcomes? A review of multilevel studies. Journal of Epidemiology and Community Health, 60, 1, 49 - 155.

Selman, R. L., Levitt, M. Z., \& Schultz, L. H. (1997). The friendship framework: Tools for the assessment of psychosocial development. In R. L. Selman, C. L. Watts, \& L. H. Schultz (Eds.), Fostering friendship: Pair therapy for treatment and prevention. New York: Aldine De Gruyter.

Simons, J., Dewitte, S., Lens ,W., (2004). The effect of different types of instrumentality on motivational and cognitive variables. British Journal of Educational Psychology, 74, 343360.

Slavin, R. E. (1987). Cooperative learning, Washington, DC: National Education

Slavin, R.E. (1998). Can education reduce social inequity? Educational Leadership, 55 (4),6-10.

Steinberg, L., \& Brown, B. (1989, March), Beyond the classroom: Family and peer influences on high school achievement. Invited paper presented to the Families as Educators special interest group at the annual meeting of the American Educational Research Association, San Francisco.

Stephens, T, M. (1976). Directive teaching ofchildren with learning and behavioral handicaps. Columbus, OH: Merrill. 
Stephens, T. M. (1981). Social behavior assessment: Technical information. Unpublished manuscript.

Strain, P. S. (1985). Programmatic research on peers as intervention agents for socially isolated classmates. In B. H. Schneider. K. H. Rubin, \& J. E. Ledingham (Eds.), Children's peer relations: Issues in assessment and intervention (pp.193-205). New York: Springer-Verlag

Su, Y.-L., \& Reeve, J. (2011). A meta-analysis of the effectiveness of intervention programs designed to support autonomy. Educational Psychology Review, 23, 159-188.

Sullivan, H. S. (1953). The interpersonal theory of psychiatry. New York: Norton

Tagiuri, R. (1968). The concept of organizational climate. In R. Tagiuri \& G. H. Litwin (Eds.), Organizational climate: Exploration of a concept. Boston: Harvard University, Division of Research, Graduate School of Business Administration.

Teddlie, C., \& Reynolds, D. (2000). The international handbook of school effectiveness research. London, UK: Falmer Press.

Thomas, W. B. (1984). Competition and cooperation as contradictory norms in urban schools: A sociological perspective. Journal of Negro Education, 53, 147-160.

Vallerand, R. J. (1997). Toward a hierarchical model of intrinsic and extrinsic motivation. In M. P. Zanna (Ed.), Advances in experimental social psychology (Vol. 29, pp. 271-360). San Diego: Academic Press.

Vallerand, R. J., Fortier, M. S., \& Guay, F. (1997). Self-determination and persistence in a reallife setting: Toward a motivational model of high school dropout. Journal of Personality and Social Psychology, 72, 1161-1176.

Vedder, P. (1985). Cooperative learning: A study on process and effects of cooperation between primary school children. Groningen: Rijksunwerscheit Groningen.

Vedder, P. Boekaerts, M., \& Seegers, G. (2005). Perceived social support and well being in school: the role of students' ethnicity. Journal of Youth and Adolescence, 34(3), 269-278.

Véronneau, M.H., Koestner, R. F., \& J. R. Abela, (2005). Intrinsic need satisfaction and wellbeing in children and adolescents : An application of the self-determination theory. Journal of Social and Clinical Psychology, 24, 280-292.

Vygotsky, L. S. (1978). Mind in society: The development of higher psychological processes. Cambridge: Harvard University Press.

Weber, G. (1971). Inner city children can be taught to read: Four successful schools (Occasional paper 18). Washington: D.C.: Council for Basic Education, October 1971.

Weinstein, C. S., \& Pinciotti, P. (1988). Changing a school yard: Intentions, design decisions, and behavioral outcomes. Environment and Behavior, 20, 345-371.

Weisner, T. S. (1998). Human development, child wellbeing, and the cultural project of development [Review]. New Directions for Child Development, 81, 69-85.

Weinstein, C. S. (1991). The classroom as a social context for learning. Annual Review Psychology, 42, 493-525 
Weinstein, N., \& Ryan, R. M. (2010). When helping helps: Autonomous motivation for prosocial behavior and its influence on well-being for the helper and recipient. Journal of Personality and Social Psychology, 98, 222-244.

Wentzel, K. (1997). Student motivation in middle school: The role of perceived pedagogical caring. Journal of Educational Psychology, 83(3), 411 - 420.

Wentzel, K. (2002). Are effective teachers like good parents? Teaching styles and student adjustment in early adolescence. Child Development, 73(1), $287-301$.

Wentzel, K. (2009). Peers and academic functioning at school. In K. H. Rubin, W. Bukowski, \& B. Laursen (Eds.). Handbook of peer interactions, relationships, and groups (pp. $531-$ 547). New York, NY: Guilford Press.

Wentzel, K. R., McNamara-Barry, C., \& Caldwell, K. A. (2004). Friendships in middle school: Influences on motivation and school adjustment. Journal of Educational Psychology, 96, $195-203$.

White, S. C. (2008). But what is wellbeing? A framework for analysis in social and development policy and practice. Paper for Regeneration and Wellbeing: Research into Practice. http://www.bath.ac.uk/cds/but_what_is\%20_wellbeing.pdf (accessed 2 June 2009).

White, K- J. \& Jones, K. (2000) Effects of Teacher Feedback on the Reputations and Peer Perceptions of Children with Behavior Problems. Journal of Experimental Child Psychology 76, 302-326.

White, K. J.; Sherman. M. D., \& Jones, K. (1996). Children's Perceptions of Behavior Problem Peers: Effects of Teacher Feedback and Peer-Reputed Status. Journal of School Psychology, 34 (1), 53-72.

White, K. J., Smith, S. G ., \& Kuzma, B. (1991). The influence of teacher feedback on children's peer preferences and perceptions: Replication and test of order effects. Paper presented at the biennial meeting of the Society for Research in Child Development, Seattle, WA, 1991.

Wigfield, A., Eccles, J.S., Schiefele, U., Roeser, R., \& Davis-Kean, P. (2006). Motivation. In N. Eisenberg (Ed.), Handbook of child psychology (Vol. 3, $6^{\text {th }}$ ed., pp. 933 - 1002). New-York, NY: Wiley.

Wilson, J. Q., \& Kelling, G. L. (1982, March). Broken windows, Atlantic Monthly. Retrieved May 2008, from http://www.theatlantic.com/doc/198203/broken-windows

Wirt, J., Choy, S., Provasnik, S., Rooney, P., Sen, A., Tobin, R., Kridl, B., \& Livingston, A. (2003). The condition of education: 2003 (NCES 2003-067). Washington, DC: National Center for Education Statistics, Institute of Education Sciences, E.S. Departament of Education. Retrived January 5, 2003, from http://nces.ed.gov/pubs2003/2003067.pdf

Wyse, A. E., Keesler, V., \& Schneider, B. (2008). Assessing the effects of small school size on mathematics achievement. Teachers College Record, 110, 1879 - 1900. 